\title{
8th WINFOCUS World Congress on Ultrasound in Emergency and Critical Care
}

\author{
Barcelona, Spain. 20-23 October 2012 \\ Published: 18 December 2012 \\ These abstracts are available online at http://www.criticalultrasoundjournal.com/supplements/4/S1
}

\section{MEETING ABSTRACTS}

\author{
A1 \\ Hemodynamic and cardiorespiratory ultrasound evaluation by intern \\ Paula Burgueño*, P Garmilla \\ Intensive Care Unit, Hospital Marqués de Valdecilla, Santander, España \\ E-mail: paula.burgue@gmail.com \\ Critical Ultrasound Journal 2012, 4(Suppl 1):A1
}

Background: The ultrasound in the ICU has proved to be a non invasive and economic technique that helps the approach in the diagnosis and management of the critical patient. Echocardiography permits diagnosis such as coronary syndrome, pericardial effusion or valvulopathies and brings us the possibility of monitoring the different aspects of shock, like cardiac function or volume respond. Furthermore, lung ultrasound allows us to approach the diagnosis of pneumothorax, pleural effusion, pulmonary edema, consolidation or interstitial disease. For all the abovementioned reasons, we believe intensive residents ought to train in this aspect.

Objective: To evaluate the resident's ability to determine the hemodynamic, cardiac and respiratory situation with a basic training in ultrasound.

Methods: We use VSCAN and lineal transducer probe to do lung ultrasounds in five different areas in each hemithorax. First we examine the parasternal area and then we use the axillar line to divide the lateral of the hemitorax in four parts: anterosuperior, anteroinferior, posteroinferior and postero superior; we are trying to evaluate the possible presence of: pleural sliding, pleural effusion, consolidation, A or B lines, and the correlation with the clinical aspects and X-rays or TC. We use VSCAN for echocardiography and evaluating the cardiac function, to check for the presence of segmentary contractility alterations, valvulopathies and cava vein variability.

We are presented with a 73-year-old patient with previous arterial hypertension, atrial fibrillation, and chronic bronchitis who is admitted in the ICU for septic shock secondary to anastomotic rupture in the postoperative of a colon disease. Thirty-two days later, he is extubated without vasoactive drugs. On the 35th day he started having respiratory problems, fever and hypotension, needing intubation and vasoactive drugs. After a subclavian access, we suspected it to be a left pneumothorax. In the X-rays, both hemithorax bases were observed with an augment of density, mostly in the right lung. A Lung ultrasound was done in the parasternal line of the right lung and we observed pleural sliding with $B$ lines pattern. It was not present in the left lung and we were not able to do the echocardiography because of window absence. TC confirmed the presence of anterior pneumothorax, and a thorax tube was inserted. The clinical situation did not improve. ECG demonstrated a new $Q$ wave in the septal face and negative $T$ in the lateral face. An echocardiography was done and moderate biventricular dysfunction, left ventricle dilated with dyskinetic movement were observed. We also noticed pericardial effusion with a dubious tamponade of the right ventricle, nonetheless this was dismissed because this collapse movement occurred in systole. There were mitral and tricuspid insufficiencies. The cava vein was dilated without variability. At a later time, another lung ultrasound was done where pleural sliding was observed in both hemithorax, with a B line pattern at the parasternal line. Pleural effusion and heterogenic consolidation were noticed at the decline parts of both lungs.

Discussion: It is a difficult patient with multiple complications that render his hemodynamic situation worse. We were not able to diagnose with certainty the presence of pneumothorax, it is true that M mode could not be done and this had increased the probability of diagnosis of it, but the ultrasound improved the chances and confirmed the drainage of the pneumothorax. We can say that it is a shock with septic and cardiac characteristics with a dilated cava vein and B lines that indicate pulmonary edema. Also bilateral consolidation lung was observed with pleural effusion that makes the pneumonia more likely, bearing in mind the fever and the respiratory problems of the patient.

Conclusion: Portable ultrasound technology is able to assist physicians in the assessment of the cardiovascular and respiratory system at the bedside of the patient.

Use of the ultrasound can lead to considerable savings of cost and time, as physicians will be able to more selectively order tests based on what is found during the physical examination and after completing a brief ultrasound study. Thus, the ultrasound has the potential to help promote better and more efficient health-care delivery.

The ultrasound is a technology observed-dependent and this is the reason for which a good training is important. More studies are necessary to evaluate the training of the residents on it.

References

1. Hemodynamic monitoring using echocardiography in the critically. Springer-Verlag Berlin Heidelberg.

2. Liechtenstein D: Ultrasound diagnosis of the critically ill. Berlin-Heidelberg: Springer-Verla, 2, 2055.

3. Colemero M, Garcia-Delgado M, Navarrete I, Lopez-Milena G: Utility of the lung ultrasound in the intensive medicine unit. Medicina Intensiva 2010, 34(9):620-628.

4. Azcarate JM Ayuela, Terre F Clau, Ochogavia A, Pereira RVicho: Role of the echocardiography in the hemodynamic monitorization of critical patients. Medicina Intensiva 2011, 36(3):220-232.

\section{A2}

Contrast enhanced ultrasound imaging of the optic nerve sheath diameter - what are we really measuring?

Andrej Bergauer ${ }^{1 *}$, G Prosen ${ }^{2}$, V Flis ${ }^{1}$, T Šeruga $^{3}$, M Brvar $^{3}$, N Kobilica ${ }^{1}$ Department for Vascular Surgery, University Clinical Center Maribor, Ljubljanska 5, Maribor, Slovenia; ${ }^{2}$ Center for Emergency Medicine,

Ulica talcev 9, Maribor, Slovenia; ${ }^{3}$ Department for Radiology, University Clinical Center Maribor, Ljubljanska 5, Maribor, Slovenia E-mail: andrej@bergauer.si

Critical Ultrasound Journal 2012, 4(Suppl 1):A2

Background: Several studies on pediatric and adult population proposed measurment of optic nerve sheath diameter (ONSD) as a noninvasive

\section{SpringerOpen ${ }^{\circ}$}


marker of increased intracranial pressure (ICP). Only few studies were made correlating MRI measurment of ONSD with ultrasound measurment of ONSD. Overall lower standard values of the ONSD for ultrasound measurment compared to MRI measurment were found. That might be atribbuted to variable interpretation of ultrasound anatomy - what are we really measuring?

Objective: We performed a proof of concept study to evaluate the accuracy of measurments of the ONSD for contrast enhanced ultrasound (CEUS) and magnetic resonance imaging (MRI). Second generation contrast agent (Sonovue ${ }^{\mathrm{TM}}$, Bracco SpA) was used to enhance the ultrasound recognition of relevant anatomy and conduct transbulbar ONSD measurments.

Patients and methods: Nine healthy volunteers were examined with CEUS with transbulbar approach and MRI. CEUS and MRI examinations were recorded on the PACS system. Measurments of the ONSD were performed on the collected images using DICOM viewing software (OsiriX ${ }^{T M}$, Pixmeo SARL). Statistical analysis was performed and included the calculation of the agreement of measurment between both methods. Statistical software was used (IBM SPSS Statistics ver. $20^{\text {TM }}$, IBM Corp).

Results: Good correlation of measurment values was found between CEUS and MRI (ICC 0.98, 95\% Cl, $0.74-0.99$ ), MRI being regarded as a gold standard.

Conclusion: Using CEUS significantly aids the identification and recognition of the relevant structures sorrounding the optic nerve. Measuring a small structure as ONSD with ultrasound is a demanding task. By using CEUS the exact measuring points can be quickly and easilly identified, making a measurment more exact using transbulbar sonography on living subjects. The measurment can be quickly performed, can be repeated, the introduced contrast agent is nontoxic

References

1. Beare NAV, Kampondeni S, Glover SJ, Molyneux E, Taylor TE, Harding SP, et al: Detection of raised intracranial pressure by ultrasound measurement of optic nerve sheath diameter in African children. Trop. Med. Int. Health 2008, 13(11):1400-4.

2. Karakitsos D, Soldatos T, Gouliamos A, Armaganidis A, Poularas J, Kalogeromitros A, et al: Transorbital sonographic monitoring of optic nerve diameter in patients with severe brain injury. Transplant. Proc 2006, 38(10):3700-6

3. Rajajee V, Vanaman M, Fletcher JJ, Jacobs TL: Optic nerve ultrasound for the detection of raised intracranial pressure. Neurocrit Care 2011, 15(3):506-15.

4. Moretti R, Pizzi B, Cassini F, Vivaldi N: Reliability of optic nerve ultrasound for the evaluation of patients with spontaneous intracranial hemorrhage. Neurocrit Care 2009, 11(3):406-10.

5. Geeraerts T, Launey Y, Martin L, Pottecher J, Vigué B, Duranteau J, et al: Ultrasonography of the optic nerve sheath may be useful for detecting raised intracranial pressure after severe brain injury. Intensive Care Med 2007, 33(10):1704-11

6. Goel RS, Goyal NK, Dharap SB, Kumar M, Gore MA: Utility of optic nerve ultrasonography in head injury. Injury 2008, 39(5):519-24.

7. Soldatos T, Chatzimichail K, Papathanasiou M, Gouliamos A: Optic nerve sonography: a new window for the non-invasive evaluation of intracranial pressure in brain injury. Emerg Med J 2009, 26(9):630-4.

8. Kimberly HH, Noble VE: Using MRI of the optic nerve sheath to detect elevated intracranial pressure. Crit Care 2008, 12(5):181.

9. McAuley D, Paterson A, Sweeney L: Optic nerve sheath ultrasound in the assessment of paediatric hydrocephalus. Childs Nerv Syst 2009, 25(1):87-90.

10. Sutherland Al, Morris DS, Owen CG, Bron AJ, Roach RC: Optic nerve sheath diameter, intracranial pressure and acute mountain sickness on Mount Everest: a longitudinal cohort study. Br J Sports Med 2008, 42(3):183-8.

11. Newman WD, Hollman AS, Dutton GN, Carachi R: Measurement of optic nerve sheath diameter by ultrasound: a means of detecting acute raised intracranial pressure in hydrocephalus. Br J Ophthalmol 2002, 86(10):1109-13.

12. Tayal VS, Neulander M, Norton HJ, Foster T, Saunders T, Blaivas M: Emergency department sonographic measurement of optic nerve sheath diameter to detect findings of increased intracranial pressure in adult head injury patients. Annals of Emergency Medicine 2007, 49(4):508-14

13. Fagenholz PJ, Gutman JA, Murray AF, Noble VE, Camargo CA, Harris NS: Optic nerve sheath diameter correlates with the presence and severity of acute mountain sickness: evidence for increased intracranial pressure. J Appl Physiol 2009, 106(4):1207-11.

14. Blaivas $M$, Theodoro D, Sierzenski PR: Elevated intracranial pressure detected by bedside emergency ultrasonography of the optic nerve sheath. Acad Emerg Med 2003, 10(4):376-81.

15. Steinborn M, Fiegler J, Kraus V, Denne C, Hapfelmeier A, Wurzinger $L$, et al: High resolution ultrasound and magnetic resonance imaging of the optic nerve and the optic nerve sheath: anatomic correlation and clinical importance. Ultraschall Med 2011, 32(6):608-13.

16. Le A, Hoehn ME, Smith ME, Spentzas T, Schlappy D, Pershad J: Bedside sonographic measurement of optic nerve sheath diameter as a predictor of increased intracranial pressure in children. YMEM American College of Emergency Physicians 2009, 53(6):785-91.

17. Rifenburg RP, Williams JJ: Optic nerve head drusen: a case of falsepositive papilledema discovered by ocular ultrasound in the emergency department. Crit Ultrasound J 2010, 2(2):75-6.

18. Soldatos T, Karakitsos D, Chatzimichail K, Papathanasiou M, Gouliamos A Karabinis A: Optic nerve sonography in the diagnostic evaluation of adult brain injury. Crit Care 2008, 12(3):R67.

\section{A3}

Ultrasound detection of septic jugular vein thrombosis

Nina Kobilica*, A Bergauer, V Flis

Surgical Clinic, Department of Vascular Surgery, University Medical Center

Maribor, Ljubljanska 5, Slovenia

E-mail: nina_kobilica@yahoo.com

Critical Ultrasound Journal 2012, 4(Suppl 1):A3

The two leading causes of IJVT are iatrogenic trauma secondary to jugular vein catheterization, and repeated IV injections by drug users. Lemierre syndrome is a complex and unusual clinical entity, characterized by septic thrombophlebitis of internal jugular vein. Lemierre syndrome was thought to be a rare and forgotten disease with suggested incidence of approximately one per million. However, an increase in frequency over the past years has been suggested due to changes in antibiotic usage. Unfortunately, wide spread antibiotic usage has also changed clinical picture of Lemierre syndrome and it is often difficult to recognize this unusual ilness in the Emergency Department (ED). Systemic septic complications may range from deep neck infection over septic arthritis to brain infections. Every organ system may be involved. Delays in diagnosis ranging up to 11 days after admission have been reported. When recognized and treated in early phase patients recover completely but other vise condition may be lethal. In emergency settings accurate and prompt diagnosis is crucial in satisfactory patient management. Diagnosis of Lemierre's syndrome is simple with Doppler ultrasonography but it mostly requires a high degree of clinical suspicion. It has been suggested that bedside ultrasound of the internal jugular vein in ED before other radiologic imaging, may lead to rapid diagnosis and treatment of Lemierre syndrome. In last two years we treated five patients with Lemierre's syndrome in our department. In one case young woman died because of sepsis and multiorgan failure due to delayed diagnosis. Rapid ultrasound examination of neck veins is discussed as a part of ED evaluation of patients.

\section{A4}

Accuracy of point-of-care ultrasound by pediatric emergency sonologists for the diagnosis of skull fractures

Joni Rabiner ${ }^{1 *}$, LM Friedman'2, H Khine', JR Avner ${ }^{1}$, JW Tsung ${ }^{2}$

${ }^{1}$ Department of Pediatrics, Division of Pediatric Emergency Medicine, Children's Hospital at Montefiore / Albert Einstein College of Medicine, Bronx, NY, USA; '2Department of Emergency Medicine, Division of Pediatric Emergency Medicine, New York, NY, USA

E-mail: JoniRabiner@gmail.com

Critical Ultrasound Journal 2012, 4(Suppl 1):A4

Background: Head trauma is one of the most common childhood injuries, accounting for $>600,000$ emergency visits annually. It is estimated that $16 \%$ of children with nontrivial head injuries may have skull fractures. There are a number of studies supporting the use of point-of-care ultrasound (PoCUS) in fracture diagnosis. However, there is limited data on the role of PoCUS for skull fracture diagnosis. 
Objective: Our objective was to determine the test performance characteristics for PoCUS performed by pediatric emergency medicine (PEM) physicians compared to CT diagnosis of skull fractures.

Patients and methods: We conducted a prospective convenience cohort study of patients up to 21 years of age who presented to two urban, level II trauma pediatric emergency departments with head injuries and suspected skull fractures requiring CT scan evaluation. After a 1-hour focused US training session, PEM attendings and fellows performed US examinations to evaluate for skull fractures. CT scan interpretations by attending radiologists were the reference standard to determine test performance characteristics of skull US. PoCUS scans were reviewed for errors by an experienced sonologist. Results: PoCUS was performed on 72 subjects with suspected skull fractures by 17 PEM physicians. The mean age was 6.5 years (SD 6.2 years) and $67 \%$ of patients were male. History and physical exam findings included scalp hematoma in $63 \%$, vomiting in $31 \%$, loss of consciousness in $13 \%$, Glasgow coma scale $<15$ in $11 \%$, and palpable fracture in $7 \%$. The prevalence of fracture was $11.1 \%(n=8)$. PoCUS for skull fracture had a sensitivity of $88 \%$ (95\% Cl 53-98\%), specificity of $97 \%$ ( $95 \% \mathrm{Cl} 89-99 \%)$, positive likelihood ratio of 28.0 (95\% Cl 7.0-112.3), and negative likelihood ratio of 0.13 (0.02-0.81). The only false negative scan was due to a skull fracture not directly under the scalp hematoma, but rather adjacent to it. US scans took a median of 65 seconds (IQR 35-139 seconds) to perform.

Conclusion: PEM physicians with focused US training were able to diagnose skull fractures in children with high specificity.

\section{A5}

Ultrassonography at Bedside in Emergency ICU: a powerful

\section{diagnostic tool}

Herbert Missaka $a^{1,2,3^{*}}$, F Leão $0^{3,4}$, LH Cantarelli, ${ }^{3,4}$, PV Dallava ${ }^{3,4}$, JEE Almeida ${ }^{3,4}$ PC Figueiredo ${ }^{3,4}$, F Nogueira $^{3,4}$, S Divan-Filho ${ }^{\prime}$, RS Lannes ${ }^{1}$, FM Vila-Da-Mota ${ }^{1,2}$ DS Usiglio ${ }^{1,2}$, G Soriano ${ }^{1,2}$, LF Jabour ${ }^{1,2}$, LC Oliveira ${ }^{1,2}$

'Intensive Care Unit 2, Hospital Municipal Souza Aguiar, Rio de Janeiro, Brazil; ${ }^{2}$ Gama Filho University Medical School, Rio de Janeiro, Brazil; ${ }^{3}$ Souza

Marques Medical School, Rio de Janeiro, Brazil; ${ }^{4}$ Programa de Orientação

Científica Medicina, Centro Cultural Tijuca, Rio de Janeiro, Brazil

E-mail: hmkmedicina@hotmail.com

Critical Ultrasound Journal 2012, 4(Suppl 1):A5

Background: Ultrasonography (USG), since the creation at 1954, is contributing as a great diagnostic tool in many medical specialties. Ultrasound has become an integral part of the practice of emergency medicine and trauma care. In this study we report 5 cases, in which USG was fundamental to diagnose and led further decisions in treatment in the Intensive Care Unit.

Objective: Identify and cases report in which USG was fundamental to diagnose and support the therapeutic choice.

Patients and methods: Observational prospective study of the patients attended at a public emergency hospital ICU, submitted to the protocol FAST extended (FAST-E), from February until June 2012.

Results: Five patients were enrolled

Case 1: A 31 year-old woman (ys), with urinary sepsis and mean arterial pressure $(\mathrm{MAP})=60 \mathrm{mmHg}$. USG evidenced hypokinesia of left ventricle, diagnosing cardiogenic shock. Dobutamine was initiated.

Case 2: $34 y$ s man, with severe brain trauma, in mechanical ventilation and $\mathrm{O} 2=100 \%, \mathrm{MAP}=70 \mathrm{mmHg}$. USG, at ER, evidenced free fluid in the hepatorenal space, and the surgery was indicated.

Case 3: 50ys woman, with respiratory insufficiency. USG diagnosed an hypertensive pneumothorax. Drainage was perfomed.

Case 4: 66ys man, victim of a spinal trauma, MAP $=75 \mathrm{mmHg}$ and inferior vena cava diameter $=28 \mathrm{~mm}$, collapsibility $<50 \%$. FAST-E protocol evidenced neurogenic shock. Norepinephrine was initiated.

Case 5: 52ys woman, related subclavian vein thrombosis treatment 2 months ago, and was referred to ER with brawny edema of the and arms. USG showed a superior vena cava thrombus and absence of line $A$ in the left pulmonary apex, featuring superior vena cava syndrome (thoracic $\mathrm{CT}$, after USG, demonstrated pulmonary artery e superior vena cava thrombus and occlusive apex tumor). Anticoagulation with LWMH was initiated.

Conclusion: The reported cases with severe diseases were diagnosed by USG examination at the ICU. The incorporation of this technology, as a routine in the ICU, demonstrated efficacy, empowered diagnostic decisions, and allowed reliably treatment.
References

1. Price $S$, Nicol E, Gibson DG: Echocardiography in the criticallyill: current and potential roles. Intensive Care Med 2006, 32:48.

2. Cholley BP, Vieillard-Baron A, Mebazaa A: Echocardiography in the ICU: time for widespread use! Intensive Care Med 2006, 32:9-10.

3. Kirkpatrick AW, Sirois M, Laupland KB, et al: Hand-held thoracic sonography for detecting post-traumatic pneumothoraces: the extended S160. Crit Care Med 2007, 35(5 (Suppl.))

\section{A6}

The comparison of airway ultrasonography and continuous waveform capnography to confirm endotracheal tube placement in cardiac arrest patients: prospective observational study

Jong Kab Noh, Young Soon Cho*

Department of Emergency Medicine, College of Medicine, Soonchunhyang

University, Korea

E-mail: choyoungsoon@hanafos.com

Critical Ultrasound Journal 2012, 4(Suppl 1):A6

Background: Ultrasound is a common examination tool in many emergency department and intensive care unit. Several studies have provided promising results of the use of ultrasound for the confirmation of endotracheal tube placement

Objective: This study aimed to assess the accuracy and timeliness of using tracheal ultrasound to examine endotracheal tube placement in cardiac arrest patients.

Patients and methods: This was a prospective, observational study, conducted at the emergency department of a university teaching hospital. Patients received emergency intubation due to cardiac arrest. Airway ultrasonography was performed during emergency intubation with the transducer placed transversely at the trachea over the suprasternal notch. Quantitative waveform capnography was used as the criterion standard for confirmation of tracheal intubation. The main outcome was the timeliness between the airway ultrasonography and the capnography.

Results: A total of 16 patients and 19 intubations were included in the analysis. The endotracheal tube was placed in the trachea in 16 intubations and in the esophagus in 3 intubations. The overall sensitivity and specificity of ultrasound to confirm tracheal intubation was $100 \%$ respectively. Capnography application times after intubation were 17.5 (10.0 32.5) seconds. The Capnograpny confirmation times after application were 30 (10 120) seconds. Ultrasound confirmation times of endotracheal tube placement after application were $5(4 \sim 5)$ seconds.

Conclusion: Ultrasound confirmation was very fast, accurate and not affected by pulmonary blood flow. Ultrasound confirmation of endotracheal tube placement is more useful in emergency department.

References

1. Neumar RW, Otto CW, Link MS, Kronick SL, Shuster M, Callaway CW, et al: Part 8: adult advanced cardiovascular life support: 2010 American Heart Association Guidelines for Cardiopulmonary Resuscitation and Emergency Cardiovascular Care. Circulation 2010, 112:S729-67.

2. Werner SL, Smith CE, Goldstein JR, Jones RA, Cydulka RK: Pilot Study to Evaluate the Accuracy of Ultrasonography in Confirming Endotracheal Tube Placement. Ann Emerg Med 2007, 49:75-80.

A7

Does bedside sonographic measurement of the IVC diameter correlate with central venous pressure (CVP) in the assessment of intravascular volume in children?

Lorraine $\mathrm{Ng}^{1^{*}}, \mathrm{H}$ Khine ${ }^{1}, \mathrm{BH}$ Taragin ${ }^{3}$, JR Avner', M Ushay ${ }^{2}$, D Nunez ${ }^{2}$ 'Department of Pediatrics, Divisions of Emergency Medicine, Children's Hospital at Montefiore/Albert Einstein College of Medicine, Bronx, NY, USA; ${ }^{2}$ Critical Care Medicine, Children's Hospital at Montefiore/Albert Einstein College of Medicine, Bronx, NY, USA; ${ }^{3}$ Department of Radiology, Children's Hospital at Montefiore/Albert Einstein College of Medicine, Bronx, NY, USA E-mail: lorraine.ng@gmail.com

Critical Ultrasound Journal 2012, 4(Suppl 1):A7

Background: Previous studies demonstrated that the collapsibility index (percent decrease in inferior vena cava (IVC) diameter with inspiration) of 
$>50 \%$ and an IVC/Aorta ratio of $<0.8$ correlated with a low intravascular volume.

Objectives: Our study sought to determine if bedside ultrasound (BUS) measurements of the IVC diameter correlate with central venous pressure (CVP) measurements as an indicator of intravascular volume status in acutely ill children.

Patients and methods: A convenience sample of children $<21$ years-old who were admitted to the pediatric critical care unit and required CVP monitoring had BUS measurements of both IVC and aortic diameters with simultaneous CVP measurement. The collapsibility index (sagittal view) and IVC/Aorta ratio (transverse view) were calculated from these measurements. A CVP $\leq 8 \mathrm{mmHg}$ was considered as a marker for decreased intravascular volume.

Results: Of the 51 participants, $21(43 \%)$ had a CVP $<8 \mathrm{mmHg}$. Eight of $51(16 \%)$ children had a collapsibility index $>50 \%$ and 8 of $43(18 \%)$ had an IVC/Aorta ratio of $<0.8$. The sensitivity of a collapsibility index $\geq 0.5$ to predict a CVP $\leq 8 \mathrm{mmHg}$ was $14 \%$, the specificity was $83 \%$, the positive predictive value was $38 \%$ and the negative predictive value was $57 \%$. Neither collapsibility index $(r=-0.23, p=0.11)$ nor IVC/Aorta $(r=-0.19, p=$ 0.22 ) correlated with CVP in assessing intravascular volume in our study population.

Conclusions: Based on these data, the IVC and aortic measurements by BUS are not reliable indicators of intravascular volume (as determined by CVP) in acutely ill children.

References

1. Brierley J, Carcillo JA, Choong K, et al: Clinical practice parameters for hemodynamic support of pediatric and neonatal septic shock: 2007 update from the American College of Critical Care Medicine. Critical Care Medicine 2009, 37(2):666-688.

2. Gorelick MH, Shaw KN, Murphy KO: Validity and reliability of clinical signs in the diagnosis of dehydration in children. Pediatrics 1997, 99(5):E6.

3. Steiner MJ, DeWalt DA, Byerley JS: Is this child dehydrated? JAMA 2004, 291:2746-54

4. Rothrock Steven G, Green Steven M, McArthur CL, DelDuca Kevin: Detection of Electrolyte Abnormalities in Children Presenting to the Emergency Department: A Multicenter, Prospective Analysis. Academic Emergency Medicine 1997, 4:1025-1031.

5. Vega RM, Avner JR: A Prospective study of the usefulness of clinical and laboratory parameters for predicting percentage of dehydration in children. Pediatric Emergency Care 1997, 13:179-182.

6. Narchi Hassib: Serum Bicarbonate and Dehydration Severity in Gastroenteritis. Archives of Disease in Childhood 1998, 78:70-71.

7. Teach SJ, Yates EW, Feld LG: Laboratory Predictors of Fluid Deficit in Acutely Dehydrated Children. Clinical Pediatrics 1997, 36:395-400.

8. Ooi Beng Suat, et al: Assessment of Dehydration in Adults Using Hematologic and Biochemical Tests. Academic Emergency Medicine 1997, 4(8):840-844.

9. Yen $\mathrm{K}$, Gorelick MH: Ultrasound applications for the pediatric emergency department: a review of the current literature. Pediatric Emergency Care 2002, 18:226-34

10. Chen L, Baker MD: Novel applications of ultrasound in pediatric emergency medicine. Pediatric Emergency Care 2007, 23:115-23.

11. Lyon $M$, Blaivas $M$, Brannam L: Sonographic measurement of the inferio vena cava as a marker of blood loss. The American Journal of Emergency Medicine 2005, 23:45-50.

12. Krause I, Birk E, Davidovits $M$, et al: Inferior vena cava diameter: a useful method for estimation of fluid status in children on haemodialysis. Nephrol Dial Transplant 2001, 16:115-23.

13. Pershad J, Myers S, Plouman C, et al: Bedside limited echocardiography by the emergency physician is accurate during evaluation of the critically ill patient. Pediatrics 2004, 114:e667-71.

14. Yanagawa Y, Nishi K, Sakamoto T, Okada Y: Early diagnosis of hypovolemic shock by sonographic measurement of inferior vena cava in trauma patients. Journal of Trauma 2005, 58:825-9.

15. Levine AC, et al: Ultrasound assessment of severe dehydration in children with diarrhea and vomiting. Society for Academic Emergency Medicine 2010, 17:1035-1041.

16. Kircher BJ, Himelman RB, Schiller NB: Noninvasive Estimation of Right Atrial Pressure from the Inspiratory Collapse of the Inferior Vena Cava. The American Journal of Cardiology 1990, 66:493-96.
17. Chen L, Hsiao A, Langhan M, Riera A, Santucci K: Use of bedside ultrasound to assess degree of dehydration in children with gastroenteritis. Society for Academic Emergency Medicine 2010, 17:1042-1047.

18. Nagdev AD, Merchant RC, Tirado-Gonzalez, Sisson CA, Murphy MC: Emergency department bedside ultrasonographic measurement of the caval index for noninvasive determination of low central venous pressure. Annals of Emergency Medicine 2010, 55(3):290-5.

19. Stawicki SP, Braslow BM, Panebianco NL, et al: Intensivist Use of HandCarried Ultrasonography to Measure IVC Collapsibility in Estimating Intravascular Volume Status: Correlations with CVP. Journal for the American College of Surgeons 2009, 209:55-61.

20. DeLorenzo RA, Morris MJ, Williams JB, et al: Does a simple bedside sonographic measurement of the inferior vena cava correlate to central venous pressure? The Journal of Emergency Medicine 2011, 42(4):429-436.

21. Bendjelid K, Romand JA, Walder B, et al: Correlation between measured inferior vena cava diameter and right atrial pressure depends on the echocardiographic method used in patients who are mechanically ventilated. J Am Soc Echocardiogr 2002, 15:944-949.

22. Hruda J, Rothuis EG, van Elburg RM, et al: Echocardiographic assessment of preload conditions does not help at the neonatal intensive care unit. American Journal of Perinatology 2003, 20:297-303.

23. Krause I, Birk E, Davidovits M, et al: Inferior vena cava diameter: a useful method for estimation of fluid status in children on haemodialysis. Nephrol Dial Transplant 2001, 16:115-23.

24. Kosiak W, Swieton D, Piskuknowicz M: Sonographic inferior vena cava/aorta diameter index, a new approach to the body fluid status assessment in children and young adults in emergency ultrasound - preliminary study. The American Journal of Emergency Medicine 2008, 26:320-325.

25. Weekes AJ, Tassone HM, Bacock A, et al: Comparison of Serial Qualitative and Quantitative Assessments of Caval Index and Left Ventricular Systolic Function During Early Fluid Resuscitation of Hypotensive Emergency Department Patients. Acad Emer Med 2011, 18:912-921.

A8

Intestinal Anisakiasis presenting as a small bowel obstruction - Pitfalls in the application of ultrasound

Masaaki Ogata

Kobe City MC West Hospital, Emergency Medicine, Kobe, Japan

E-mail: m-ogata@kobe-nishishimin-hospi.jp

Critical Ultrasound Journal 2012, 4(Suppl 1):A8

Background: Intestinal Anisakiasis is a relatively rare disease, which is related to the ingestion of raw or undercooked fish. It often presents as acute abdomen, and may mimic acute appendicitis, peritonitis and small bowel obstruction. It may be explored by laparotomy, although it usually resolves with conservative treatments.

Objectives: The purpose of the study is to evaluate the usefulness of ultrasound in the diagnosis of intestinal Anisakiasis presenting as a small bowel obstruction.

Patients and methods: Seven patients with intestinal Anisakiasis presenting as a small bowel obstruction, who were admitted in the Kobe City Medical Center West Hospital between June 2009 and May 2012, were included in the study. The final diagnosis was made clinically on the basis of medical history, clinical pictures and imaging findings in addition to serology (specific IgE to Anisakis measured with Pharmacia CAP system). We retrospectively reviewed clinical features, ultrasonograms and CT images of the cases, and compared the efficacy of ultrasound with that of CT scan in the diagnosis of intestinal Anisakiasis.

Results: All of the cases had a significant level of specific lgE to Anisakis. A present history of eating some kinds of raw fish was confirmed a couple of days before they presented to the emergency department with complaints of abdominal pain and/or distension. No past history of laparotomy was identified in 6 of them. Both ultrasound and CT scan showed the evidence of small bowel obstruction, showing dilated small bowel (7/7) and accumulation of peritoneal fluid (6/7). CT scan demonstrated segmental wall thickening and stenosis with submucosal edema distal to the dilated small bowel in all, but ultrasound demonstrated the finding in 4 of 7 cases. 
Conclusions: Ultrasound was useful in showing dilated small bowel and peritoneal fluid, but inferior to CT scan in demonstrating segmental intestinal edema causing a small bowel obstruction in cases of intestinal Anisakiasis.

Reference

1. Ido K, et al: Sonographic diagnosis of small bowel anisakiasis. J Clin Ultrasound 1998, 26:125-130.

\section{A9}

Utility of a transabdominal ultrasound-guided method with digital rectal examination for difficult urethral catheterization

Toru Kameda*, M Fujita, A Isaka, M Ozawa

Department of Emergency Medicine, Red Cross Society Azumino Hospital,

Azumino, Japan

E-mail: kamekame@pb3.so-net.ne.jp

Critical Ultrasound Journal 2012, 4(Suppl 1):A9

Objective: We evaluated the utility of a transabdominal ultrasoundguided method with digital rectal examination performed by emergency medical personnel for difficult male urethral catheterization.

Methods: This study investigated male patients in whom standard urethra catheterization attempted by an emergency nurse or emergency physician failed in our institution or who were transferred from other hospitals or nursing homes following failure of the procedure and subsequent urethral bleeding. Patients with a history of urological surgery were excluded. Transabdominal ultrasonography was performed using a portable device with a 2-5 MHz convex probe. First, an emergency physician placed the probe on the suprapubic region longitudinally and observed the possible course of the prostatic to bulbar urethra, and tried to detect the tip of a catheter advanced by a nurse until progress was obstructed. To detect the tip more easily, the physician asked the nurse to oscillate the catheter and moved the tip when necessary. After the tip was detected, the nurse withdrew $2-3 \mathrm{~cm}$. The physician then inserted the index finger of the opposite side into the rectum and kept pushing the site of the previous resistance ventrally while simultaneously holding the probe. After following these procedures, the nurse advanced the catheter again.

Results: Five patients (age range, 56-93 years) were enrolled between March 2011 and April 2012. The tip of the catheter was observed in the bulbomembranous urethra or the false passage with transabdominal ultrasonography in four of the five patients. In these four patients, the false passage was compressed or the curve of the bulbomembranous urethra became gentle by pushing the regions ventrally from the rectum, and the tip was advanced smoothly to the bladder.

Conclusion: This transabdominal ultrasound-guided method with digital rectal examination performed by emergency medical personnel appears useful for overcoming difficult urethral catheterization in some male patients.

\section{A10}

Formation of ecocardiografia in critics' area with malingerer VIMEDIX

Raul Manuel Vicho Pereira

Clinica USP-Palmaplanas, Medicina Intensiva, Palma de Mallorca, Spain E-mail: ucirvp@yahoo.es

Critical Ultrasound Journal 2012, 4(Suppl 1):A10

We realize a transthoracic (TTE) and transesophageal echocardiography (TOE) course for Anesthesia Department specialized in resuscitation with periopertative care cardiac surgery. The teacher was Raul Vicho, echocardiography teacher accredited by the Spanish Society of Intensive Medicine and Coronary Units (SEMICYUC).

Objective: To demonstrate if a theoretical - practical TTE and TOE course with the malingerer VIMEDIX 10 days, it was sufficient to acquire a level for the exercise of being technical in this service.

Method: The duration of the course was 10 days in view of theoretical classes (40 hours) and 60 hours of simulation (TOE and TTE with 40 pathological suppositions) and transthoracic studies in patients for 4 Anesthetists combining TTE and TOE probe. The theoretical program was:

1) Basic concepts of planes and doppler.

2) Hemodinamics ventricular right function.

3) Pericardium
4) Acute Aortic Syndrome

5) Image Planes

6) Valvulart heart disease

7) Masses, tumors and endocarditis.

The studies in patients have been completed by a report written for the area of the critical patient checked by the teacher. At the end of the course they realized an examination of 30 representative questions of the formation type test, evaluation practises of acquisition of planes of TTE and TOE and 10 clinical representative cases.

Results: The results of the examination was $>75 \%$ corrects answers, $>8$ corrects cases and they acquired $>80 \%$ of planes of TTE and TOE. They manage to acquire in 7 minutes 15 TOE standars. They did TTE report of sufficient quality to continue doing it in the patients' area.

Conclusion: A course given by a teacher of the SEMICYUC with malingerer VIMEDIX of 10 days is equivalent to the formation of a supporting level IIb of the SEMICYUC in TTE of the critical patient or to the advaced of European Company of Intensive Medicine. TOE basic level qualifies them to realize basic studies without issuing reports.

A11

Barriers to credentialing emergency physicians in ultrasound use Bret P Nelson*, J Mahesri, A Huang

Department of Emergency Medicine, Mount Sinai School of Medicine, New York, USA

E-mail: bret.nelson@mountsinai.org

Critical Ultrasound Journal 2012, 4(Suppl 1):A11

Background: Ultrasound training and hospital credentialing guidelines were established by the American College of Emergency Physicians (ACEP) in 2001. Training during residency has become the norm yet the penetration of hospital credentialing for practicing emergency physicians is unknown.

Objective: To investigate the availability of emergency ultrasound credentialing and what barriers to credentialing exist.

Patients and methods: An online survey was distributed through the ACEP ultrasound section. It consisted of questions regarding credentialing pathways, ultrasound use, and barriers to credentialing.

Results: Of 195 respondents, $85 \%$ were board certified in emergency medicine with a mean age of 40 years. $69 \%$ practiced in academic hospitals, $27 \%$ in community, and $4 \%$ in military. $83 \%$ worked in departments with annual volumes $>40,000$ visits and $92 \%$ had an emergency ultrasound director. Credentialing mechanisms existed for $96 \%$ of respondents; $51 \%$ of hospitals used ACEP guidelines for credentialing. Credentialed respondents were credentialed in: FAST (78\%), Vascular (74\%), Aorta (68\%), OB/Gyn (66\%), Gallbladder (55\%), Renal (53\%), and DVT $(40 \%)$. Non-credentialed respondents most commonly cited "lack of experience" (35\%) and "too busy" $(29 \%)$ as barriers. Academic and community physicians were credentialed at the same rate. Those who completed training prior to 2001 were less likely to be credentialed than those trained after in all areas except gallbladder ultrasound. Financial incentive (34\%) and hands on experience (31\%) were most often cited as reasons to pursue credentialing. This was true for those trained before or after 2001, and for academic or community practice.

Conclusion: While most surveyed centers allow for credentialing, many physicians are still not credentialed. Based on these results, targeting physicians trained prior to 2001 with financial incentives and opportunities for hands-on ultrasound experience may be of benefit.

Reference

1. ACEP policy statement on emergency ultrasound guidelines. Ann Emerg Med 2009, 53:550-570.

A12

Small retained foreign bodies: what is the limit of detection using current emergency ultrasound equipment?

Daniel Jafari ${ }^{1 *}, \mathrm{KJ} \mathrm{Cody}^{1}, \mathrm{NL}$ Panebianco ${ }^{1}$, FS Shofer ${ }^{1}, \mathrm{BS} \mathrm{Ku}{ }^{2}, \mathrm{~A} \mathrm{Au}^{2}, \mathrm{AJ}$ Dean ${ }^{1}$

${ }^{1}$ Department of Emergency Medicine, Hospital of the University of

Pennsylvania, Philadelphia, PA, USA; ${ }^{2}$ Department of Emergency Medicine,

Thomas Jefferson University Hospital, Philadelphia, PA, USA

E-mail: daniel.jafari@uphs.upenn.edu

Critical Ultrasound Journal 2012, 4(Suppl 1):A12 
Background: Previous studies of small foreign bodies (FB) have shown a wide range of accuracies of $F B$ detection using animal models, with high accuracy rates for $F B>10 \mathrm{~mm}$ and variable accuracy rates for 4 to $5 \mathrm{~mm}$ FB.

Objective: To determine the lower limit of sonographic detection of FB using current emergency ultrasound equipment in a soft tissue model. Methods: FBs made of metal, glass, wood, and plastic (3 of each) $1 \times 1 \times$ $3 \mathrm{~mm}$ in size were placed at a depth of $0.5-2.0 \mathrm{~cm}$ in 12 pork feet. 8 feet were punctured without FB placement. Pork feet were submerged during this process to minimize air in tissue. 7 ED sonologists with $>2$ years experience were blinded to overall number, type and depth of $F B$, but not to size. FB sites were scanned by each sonologist using either a hockey stick or traditional linear array transducer in a randomized preassigned order. Sonologist confidence in the diagnosis was reported using a visual analog scale for each site. Sensitivity, specificity, positive and negative predictive values (PPV and NPV) with 95\% confidence intervals were calculated. To determine if sonologist confidence differed by perceived presence or absence of a foreign body, paired t-test was used.

Results: 140 ultrasound scans were performed which reported sensitivity, specificity, PPV and NPV as 50\% (95\% Cl: 39\%-61\%), 50\% (37\%-61\%), 60\% (48\%-72\%), and $40 \%$ (28\%-52\%) respectively. There was little agreement among the sonologists (only 2 sites with $100 \%$ agreement). Sensitivity ranged from $25 \%$ to $75 \%$, specificity $37 \%$ to $62 \%$, PPV $42 \%$ to $75 \%$, and NPV $25 \%$ to $57 \%$ for each sonologist. Sonologists were more confident reporting a positive result $(81 \%$ vs $51 \%, p<0.0001)$, irrespective of the actual presence of FB. The difference between detection rates of 4 types of FB did not reach statistical significance.

Conclusion: Current emergency ultrasound equipment utilized by ED sonologists is unreliable in detection of $3 \mathrm{~mm} F B$ in a human extremity soft tissue model. Future studies may further delineate accuracy rates among different sizes and materials of FB.

\section{A13}

Is training in basic echocardiography feasible in junior doctors? Julina Md Noor ${ }^{1 *}$, F Mohd Salleh ${ }^{2}$

${ }^{1}$ Faculty of Medicine, Universiti Teknologi MARA, Malaysia; ${ }^{2}$ Emergency \&

Trauma Department, Sungai Buloh Hospital, Malaysia

E-mail: julinamn@gmail.com

Critical Ultrasound Journal 2012, 4(Suppl 1):A13

Background: In bedside ultrasound teaching, it has been generally accepted that Focused Assessment with Sonography in Trauma (FAST) is well received by medical students and junior doctors. However there is no evidence to date on the training of bedside basic echocardiography among junior doctors. As echocardiography is a quick and non-invasive diagnostic tool in the emergency department, the inclusion of this into junior doctors training should be a logical step.

Objective: This study aims to demonstrate the feasibility of training basic echocardiography among junior doctors.

Patients and methods: Junior doctors with no previous exposure or formal training in basic echocardiography were given an initial 5-hour theoretical and practical basic echocardiography training. They were given a pre and post assessment in the form of an objective structured clinical examination (OSCE). Following this, the doctors were required to complete 10 supervised echocardiography by emergency physicians trained in focused echocardiography. After 3 weeks, a theory and practical assessment was held by an independent observer. Participants also filled a feedback form on the perception of the training.

Results: Results demonstrated that the junior doctors were able to perform satisfactorily and the level of confidence in performing basic echocardiography was higher after the training. They also felt that this training should be instituted for junior doctors and intended to seek further echocardiography training.

Conclusion: Training basic echocardiography among junior doctors is feasible and increases performer confidence.

\section{References}

1. Gogalniceanu PJ, Sheena Y, Kashef E, Purkayastha S, Darzi A, Paraskeva P. Is basic emergency ultrasound training feasible as part of standard undergraduate medical education? J Surg Educ 2010, 67(3):152-156.
2. Mandayia DP, Aragona J, Chan L, Chan D, Henderson SO: Ultrasound training for emergency physicians-a prospective study. Acad Emerg Med 2000, 7(9):1008-1014.

\section{A14}

Point-of-care ultrasound in patients with aortic dissection - two year experience at Ljubljana Emergency Medical Unit

Hugon Možina ${ }^{1^{*}}$, B Jug $^{2}$, M Podbregar $^{3}$

${ }^{1}$ Emergency Medical Unit, University Medical Centre Ljubljana, Zaloška 7, Ljubljana, Slovenia; ${ }^{2}$ Dept. of Vascular Diseases, University Medical Centre Ljubljana, Slovenia; ${ }^{3}$ Dept. of Intensive Care Medicine, University Medical Centre Ljubljana, Slovenia

E-mail: hugon.mozina@kclj.si

Critical Ultrasound Journal 2012, 4(Suppl 1):A14

Background: Aortic dissection (AD) is associated with high morbidity and mortality; mortality rates increase by $1-2 \%$ per hour1, therefore timely diagnosis is pivotal. Point-of-care ultrasound (PoCUS) narrows the number of differentials in patients with shock, chest pain and shortness of breath2; however, reports addressing its routine use in the ER are scarce. Objective: Retrospective assessment of factors influencing use of PoCUS and its impact on time-to-diagnosis in patients with AD.

Patients and methods: We reviewed medical records and charts of patients with confirmed diagnosis of acute AD between May 2010 to May 2012.

Results: Twenty-seven patients (out of 45.630 presenting to the ER) with AD were identified (19 type A, 8 type B; 13 with typical clinical presentation). Diagnosis was confirmed with contrast enhanced CT in 25 patients, and with PoCUS (during CPR) and autopsy in two. 14 (52\%) had prior PoCUS (11 confirmed, 3 supported the diagnosis). PoCUS did not affect time-todischarge from the ER significantly $(87,60-120$ vs. $120,102-240$ minutes, $\mathrm{p}=0.179$ ). PoCUS was performed more often in unstable patients (100 vs. $38.1 \%$ stable, $\mathrm{p}=0.09$ ) and in patients with equivocal clinical presentation ( $30.8 \%$ vs. $71.4 \%$ in typical presentation, $p=0.038$ ). On a multivariate model, atypical clinical presentation emerged as an indenpedent predictor of PoCUS use after adjustment for age, gender, and hemodynamic stability $(\mathrm{p}=0.047)$.

Conclusion: Our findings suggest that point-of-care ultrasound is increasingly used in the initial ER management of patients with $A D$, especially in hemodynamically unstable patients and in patients with atypical clinical presentation.

\section{References}

1. Agnostopoulos CE, Prabhakar MJS, Kittle CF: Aortic dissections and dissecting aneurysms. Am J Cardiol 1972, 30:263-71.

2. Jones AE, Tayal VS, Sullivan DM, Kline JA: Randomized, controlled trial of immediate versus delayed goal-directed ultrasound to identify the cause of nontraumatic hypotension in emergency department patients. Crit Care Med 2004, 32:1703-8.

3. von Kodolitsch Y, Schwartz AG, Nienaber CA: Clinical prediction of acute aortic dissection. Arch Intern Med 2000, 160:2977-82.

4. $2010 \mathrm{ACCF} / \mathrm{AHA} / \mathrm{AATS} / \mathrm{ACR} / \mathrm{ASA} / \mathrm{SCA} / \mathrm{SCAI} / \mathrm{SIR} / \mathrm{STS} / \mathrm{SVM}$ guidelines for the diagnosis and management of patients with thoracic aortic disease: a report of the American College of Cardiology Foundation/American Heart Association Task Force on Practice Guidelines, American Association for Thoracic Surgery, American College of Radiology, American Stroke Association, Society of Cardiovascular Anesthesiologists, Society for Cardiovascular Angiography and Interventions, Society of Interventional Radiology, Society of Thoracic Surgeons, and Society for Vascular Medicine. Circulation 2010, 121(13):1544-1579.

\section{A15}

Point-of-care ultrasound diagnosis in seizures - A case report

Monica Puticiu

University Vasile Goldis, Arad, Romania

E-mail: puticiumonica@yahoo.com

Critical Ultrasound Journal 2012, 4(Suppl 1):A15

Background: Systemic lupus erythematosus is a autoimmune disease that can affect any part of the body. 
Seizure is a usual presentation at Emergency Department but systemic lupus erythematosus is a rare presentation.

We report a 21 years young women case present to Emergency Department with five seizures on the night. She was diagnosed two years ago with systemic lupus erythematosus and she was two weeks after caesarian surgery. She was confused and with right hemiparesis and Babinski sign. She had peripheral edema.

Methods: We used point-of-care ultrasound to evaluate this young women.

We want to evaluate brain edema and we measured the optic nerve.

Results: We find left and right optic nerve dimension $4.3 \mathrm{~mm}$. We find bilateral pleural effusion, pericardial and abdominal effusion.

Conclusion: Point-of-care ultrasound is a rapid and helpful tool in evaluation of the severity of systemic lupus erythematosus

The enlarged of optic sheath, $4.3 \mathrm{~mm}$ is not associate with brain edema on computed tomography.

References

1. Lichtenstein D: Whole body ultrasonography in the critically ill. 2010, 245-247.

2. Noble V, Nelson B, Sutingco N: Manual of emergency and critical care ultrasound. 2007, 175-181.

3. Victor M, Ropper A: Principles of neurology. 2001, 909.

4. Şerban V, Babeş P: Clinică medicală, teorie şi practică. 1999, 255-274.

\section{A16}

Ultrasound guidance for bedside placement of peripherally inserted central catheter in pediatric patients

Juan José Menéndez Suso

Pediatric Critical Care Department, La Paz Universitary Hospital, Madrid, Spain E-mail: juanjomen@yahoo.es

Critical Ultrasound Journal 2012, 4(Suppl 1):A16

Background: Studies conducted in adults have revealed that ultrasound (US) guidance for peripherally inserted central catheter (PICC) placement may improve success rate and reduce procedural complications. However, this is still not sufficiently studied in children.

Objective: To study the safety and efficacy of US-guidance for bedside PICC placement in children.

Patients and methods: Prospective observational study in which 50 US guided PICC placement attempts are analyzed. Patient clinical data, procedural details, and infectious and thrombotic complications of the catheters are described.

Results: Median age and weight of the patients were 55 months (7-288) and $15 \mathrm{~kg}$ (3.2-80), respectively. The veins selected for PICC placement were basilic vein in $73 \%$ patients, brachial vein in $14.5 \%$, cephalic vein in $6.3 \%$ and external yugular vein in $6.2 \%$. Intravenous sedo-analgesia was administered in $93 \%$ of the patients. Successful PICC placement was achieved in $96 \%$ of attempts. Success rate was $42 \%$ in the first attempt, $58 \%$ in the second, and $79 \%$ in the third. Procedural complication rate was very low $(8 \%)$, with moderate local hemorrhage and accidental arterial puncture incidence of $6 \%$ and $2 \%$, respectively. The median time spent on the procedure was 28 minutes (15-90). The median cannulation time was 3.5 minutes (0.5-60). Median PICC dwell time was 17 days (4-59). Central line-associated bloodstream infection (CLABSI) was suspected in three cases but it was finally not confirmed in any case. Weekly echo-doppler exploration of the cannulated veins detected superficial vein thrombosis in $6.3 \%$ of the patients and deep vein thrombosis in $2 \%$. No patients showed clinical signs of venous thrombosis.

Conclusion: Ultrasound-guided PICC cannulation is safe, rapid, and has a high success rate in children.

References

1. de Carvalho Onofre PS, da Luz Gonçalves Pedreira M, Peterlini MA: Placement of peripherally inserted central catheters in children guided by ultrasound: a prospective randomized, and controlled trial. Pediatr Crit Care Med 2012, 13(5):1-6.

2. Nichols I, Doellman D: Pediatric peripherally inserted central catheter placement: application of ultrasound technology. J Infus Nurs 2007, 30(6):351-6.

3. Donaldson JS, Morello FP, Junewick JJ, O'Donovan JC, Lim-Dunham J: Peripherally inserted central venous catheters: US-guided vascular access in pediatric patients. Radiology 1995, 197(2):542-4.

\section{A17}

What are the baseline measurements for physeal plate widths in healthy, uninjured children?

Lorraine $\mathrm{Ng}^{*}$, JA Martin, RE Lewiss

St. Luke's Roosevelt Hospital Center, Department of Emergency Medicine, Division of Emergency Ultrasound, New York, NY, USA

E-mail: lorraine.ng@gmail.com

Critical Ultrasound Journal 2012, 4(Suppl 1):A17

Background: There is limited data on the sonographic evaluation of normative physeal plate measurements in healthy, uninjured children.

Objectives: To determine the baseline measurements for physeal plate widths in healthy, uninjured children.

Methods: This is a prospective observational study of a convenience sample of healthy patients between ages 0 and 12 years presenting to the pediatric emergency department. A focused ultrasound of the distal tibia, fibula, radius and ulna were performed bilaterally (8 total). Measurements were taken at the physeal plates in the longitudinal plane at the widest distance. The degree of variance of physeal plate widths within an individual and the average values of physeal plates for each bone were calculated.

Results: A total of 60 patients were enrolled in this study. The mean age of enrolled patients was 6 years 3 months, $38 \%$ of who were female. Mean physeal plate diameters for the averaged measurement of each bone were: tibia $0.33 \mathrm{~cm}(95 \% \mathrm{Cl} 0.29-0.36)$, fibula $0.31 \mathrm{~cm}(95 \% \mathrm{Cl} 0.28-0.34)$, radius $0.27 \mathrm{~cm}(95 \% \mathrm{Cl} 0.24-0.30)$ and ulna $0.32 \mathrm{~cm}(95 \% \mathrm{Cl} 0.27-0.36)$. Mean values for the absolute difference in physeal plate diameters were: tibia 0.06 $\mathrm{cm}(95 \% \mathrm{Cl} 0.04-0.07)$, fibula $0.06 \mathrm{~cm}(95 \% \mathrm{Cl} 0.04-0.07)$, radius $0.05 \mathrm{~cm}$ $(95 \% \mathrm{Cl} 0.04-0.07)$, and ulna $0.1 \mathrm{~cm}(95 \% \mathrm{Cl} 0.05-0.16)$. When measurements were stratified by age, the confidence intervals for each averaged measurement narrowed with increasing age while the absolute difference in physeal plate diameters remained consistent.

Conclusion: This pilot study demonstrated that there was no statistically significant difference in physeal plate diameters between contralateral extremities and the degree of variation between contralateral extremities was minimal. Results of this study elucidate normative growth plate variance in healthy children and demonstrate that mean plate measurements and absolute differences are narrow. This study suggests that sonographic detection of significant disparities in physeal plate diameters of injured children may have the potential for earlier detection of Salter Harris injuries with subsequent appropriate referral and management.

\section{References}

1. Chamberlain JM, Patel KM, Pollack MM, et al: Recalibration of the pediatric risk of admission score using a multi-institutional sample. Ann Emerg Med 2004, 43:461.

2. Wilkins KE, Aroojis AJ: Incidence of fractures in children. In: Rockwood \& Wilkins' Fractures in Children. Lippincott Williams \& Wilkins, Philadelphia: Beaty, JH, Kasser, JR, 6 2006, 12

3. Carson S, Woolridge DP, Colletti J, Kilgore K: Pediatric upper extremity injuries. Pediatr Clin North Am 2006, 53:41.

4. Peterson HA, Madhok R, Benson JT, et al: Physeal fractures: part 1. Epidemiology in Olmsted County, Minnesota, 1979-1988. J Pediatr Orthop 1994, 14:423.

5. Sankar WN, Chen J, Kay RM, Skaggs DL: Incidence of occult fracture in children with acute ankle injuries. J Pediatr Orthop 2008, 28(5):500-1.

6. Simanovsky N, Hiller N, Leibner E, Simanovsky N: Sonographic detection of radiographically occult fractures in paediatric ankle injuries. Pediatr Radiol 2005, 35(11):1062-5.

7. Farley FA, Kuhns L, Jacobson JA, DiPietro M: Ultrasound examination of ankle injuries in children. Journal of Pediatric Orthopedics 2001, 21:604-607.

8. Gleeson AP, Stuart MJ, Wilson B, Phillips B: Ultrasound assessment and conservative management of inversion injuries of the ankle in children: Plaster of paris vs. tubigrip. Journal of bone and joint surgery 1196, 78-B:484-7.

\section{A18}

Human or animal? Finding the best ultrasound soft tissue model for foreign body evaluation

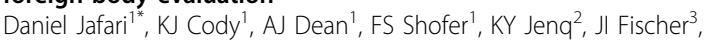
NL Panebianco ${ }^{1}$

'Department of Emergency Medicine, Hospital of the University of Pennsylvania, Philadelphia, PA, USA; ${ }^{2}$ Department of Emergency Medicine, 
Pennsylvania Hospital, Philadelphia, PA, USA; ${ }^{3}$ Department of Emergency Medicine, Thomas Jefferson University Hospital, Philadelphia, PA, USA E-mail: daniel.jafari@uphs.upenn.edu Critical Ultrasound Journal 2012, 4(Suppl 1):A18

Background: A variety of animal models have been used for research into the sonographic evaluation of soft tissue foreign bodies. The wide range of reported accuracies in FB detection in these studies may be due to some tissue models being easier to image than human tissue.

Objective: To determine which among commonly used animal tissue models for FB detection most closely approximates human soft tissue.

Methods: 99 sonographic images (59 still, 40 video clips) of soft tissues from healthy humans, chicken breasts and thighs, turkey thighs, beef chops and pork feet were obtained using a high frequency linear transducer. Video clips were 6 seconds and the scanning depth was 1.5 to $3.3 \mathrm{~cm}$. Clips and images were grouped separately in random order, and consisted of hand (4 stills, 6 clips), arm $(3,2)$, foot $(6,3)$, leg $(4,2)$, flank $(2,4)$, chicken breasts $(5,5)$, chicken thighs $(7,2)$, turkey thighs $(8,6)$, beef chops $(8,3)$, and pork feet $(13,7) .7$ experienced ED sonologists reviewed images and rated as "human tissue", "non-human tissue", or "don't know". Responses were converted into a binary variable, and raw percentages per sonologist and per animal type were calculated. To determine which animal tissue was most frequently identified as human, logistic regression was used clustering on sonologist.

Results: Correct identification rate was $67 \%$ for the trunk, $57 \%$ for the hand and leg, $37 \%$ for the arm, and $17 \%$ for the foot. For animal tissue models, the rate of identification as human tissue was $61 \%$ for the pork feet, $35 \%$ for the chicken thighs, $26 \%$ for the beef chops, $23 \%$ for the turkey thighs, and $13 \%$ for the chicken breasts. Pork feet were the most likely animal tissue to be identified as human tissue ( $p<0.0001, \mathrm{OR}=1.9,95 \% \mathrm{Cl} 1.2-3.0)$, and chicken breasts were the least $(p<0.0001, \mathrm{OR}=0.16,95 \% \mathrm{Cl} 0.07-0.35)$.

Conclusion: Among animal tissues, pork feet most closely approximate human tissues. Experienced sonologists performed poorly in distinguishing human from animal tissue. Educational programs and future studies might be optimized by the use of this animal soft tissue model.

\section{A19}

Accuracy of point-of-care ultrasound for diagnosis of elbow fractures in children

Joni E Rabiner ${ }^{1 *}, \mathrm{H}_{\text {Khine }}^{1}$, JR Avner ${ }^{1}$, LM Friedman², JW Tsung ${ }^{2}$

'Department of Pediatrics, Division of Pediatric Emergency Medicine,

Children's Hospital at Montefiore / Albert Einstein College of Medicine,

Bronx, NY, USA; ${ }^{2}$ Department of Emergency Medicine, Division of Pediatric

Emergency Medicine, New York, NY, USA

E-mail: JoniRabiner@gmail.com

Critical Ultrasound Journal 2012, 4(Suppl 1):A19

Background: Ultrasound (US) has been shown to be useful in the diagnosis of pediatric skeletal injuries. It can be performed accurately and reliably by emergency department (ED) physicians with focused US training.

Objective: To determine the test performance characteristics for point-ofcare US performed by pediatric emergency medicine (PEM) physicians compared to radiographic diagnosis of elbow fractures and to compare inter-rater agreement between enrolling physicians and an experienced PEM sonologist.

Patients and methods: This was a prospective study of children up to 21 years old presenting to the emergency department with elbow injuries requiring X-rays. Before obtaining X-rays, PEM physicians performed a focused elbow US. A positive US for fracture at the elbow was defined as the PEM physician's determination of an elevated posterior fat pad (PFP) and/or lipohemarthrosis (LH) of the PFP. All patients received an elbow X-ray in the ED and clinical follow-up. The gold standard for fracture was fracture on initial or follow-up X-rays.

Results: One hundred thirty patients with a mean age of 7.5 years were enrolled by 26 sonologists. Forty-three (33\%) patients had an X-ray positive for fracture. A positive elbow US had a sensitivity of $98 \%(95 \% \mathrm{Cl}$ $88-100 \%)$, specificity of $70 \%(95 \% \mathrm{Cl} 60-79 \%)$, positive likelihood ratio of 3.3 (95\% Cl 2.4-4.5), and negative likelihood ratio of $0.03(95 \% \mathrm{Cl} 0.01$ 0.23 ) for fracture. The inter-rater agreement (kappa) was 0.77 . The use of elbow US would reduce X-rays in $48 \%$ of patients but would miss 1 fracture.
Conclusion: Point-of-care US is highly sensitive for elbow fractures, and a negative US may reduce the need for X-rays in children with elbow injuries. Elbow US may be useful in settings where radiography is not readily accessible or time-consuming to obtain.

\section{A20}

Usefulness of bedside ultrasound in the detection of body packers in the Emergency Department

Tomas Villen ${ }^{1 *}$, M Garin 1, J Castañeda², M Sanchez¹, R Penedo', M Zamorano', D Ly' ${ }^{1}, \mathrm{~L}$ Diaz ${ }^{1}, \mathrm{~F}$ Roldan ${ }^{1}$

${ }^{1}$ Emergency Ultrasound Division, Emergency Department, Hospital

Universitario Ramon y Cajal, Madrid, Spain; ${ }^{2}$ Santander-Laredo Family

Medicine Training Unit. Spain

E-mail: tomasvillen@gmail.com

Critical Ultrasound Journal 2012, 4(Suppl 1):A20

Background: Ultrasound is not used to take part in the clinical approach of body-packers in the Emergency Department. Its usefulness in the evaluation of these kind of patients has not been sufficiently studied. Sometimes, specially in liquid-filled packs, the identification can be specially challenging. Objective: To assess the diagnostic accuracy of bedside ultrasound detecting body packers among a small size of body packers and health volunteers.

Methods: This was a prospective study, in which 29 people were enrolled. In each patient, a 6 seconds retrospective clip of each 9 abdomen anatomical division was recorded. In order to ensure adequate blinding, the clips were reviewed days after its obtention and the reviewer was blinded to all significative data as medical record number or the sonographer that saved the clip. A possitive case consists on the detection of a pack, as an hyperechoic stripe just below the peritoneum line with accoustic shadow and without peristalsis motion and/or air reverberation artifacts. The gold standard was expulsion of at least 10 packs after the scan, and we asume that healthy volunteers enrolled had no packs in their digestive tracts.

Results: 27 of 29 patients enrolled were included to analysis, due to a failure to save all the clips. 15 patients were body packers brought in to the Emergency Department under arrest from Madrid Barajas International Airport, and 12 were healthy volunteers. After the review, the accuracy obtained was (with a 95\% Confidence Interval): Sensitivity 0.8 (0.6-1), Specificity 0.5 (0.22-0.78), PPV 0.67 (0.45-0.88), NPV 0.67 (0.36-0.97), PLR 1.6 (0.86-2.97), NLR 0.4 (0.13-1.28).

Conclusion: The study shows an acceptable value of sensitivity of ultrasound in the body packers detection. Due to the small sample size and the problems related to blinding (mainly impossibility of make pressure over the bowel loops in order to distinguish them from packs) further studies are neccesary to assess the real accuracy of ultrasound among these kind of patients.

A21

Evaluation of formal training in clinical ultrasonography and its utility in identifying treatable causes of PEA

Ramon Nogué Bou*, J Fabregat, R Vilella, A Encinas, T Villen, R Campos Hospital Montserrat, University of Lleida, Alcalde Sol, № 6-3, Lleida, Spain

E-mail: rnogueb@gmail.com

Critical Ultrasound Journal 2012, 4(Suppl 1):A21

Background: Ultrasonography performed by the clinical physician should be a diagnostic tool, associated with anamnesis and physical examination of the patient, in order to increase security in the diagnoses, procedures, initial treatments and the following monitorization.

\section{Table 1(abstract A21)}

\begin{tabular}{llll}
\hline \multicolumn{4}{c}{ \% of correct answers by video } \\
\hline & Correct & Wrong & Total \\
\hline Severe hypocontractility & $208(75.1 \%)$ & $69(24.9 \%)$ & 277 \\
Pericardial effusion & $262(93.9 \%)$ & $17(6.1 \%)$ & 279 \\
Without pathology & $197(72.7 \%)$ & $74(27.3 \%)$ & 271 \\
Right ventricle dilation & $262(93.2 \%)$ & $19(6.8 \%)$ & 281 \\
\hline
\end{tabular}


Table 2(abstract A21)

\begin{tabular}{|c|c|c|c|c|c|c|}
\hline \multicolumn{7}{|c|}{ Breakdown of the confusions in the wrong answered questions } \\
\hline & Severe hypocontractility & Pericardial effusion & Without patology & Right ventricle dilation & Other answers & Total \\
\hline Severe hypocontractility & - & $7(10.1 \%)$ & $38(55.1 \%)$ & $14(20.3 \%)$ & $10(14.5 \%)$ & 69 \\
\hline Pericardial effusion & $4(23.5 \%)$ & - & $9(52.9 \%)$ & $4(23.5 \%)$ & $0(0.0 \%)$ & 17 \\
\hline Without pathology & $16(21.6 \%)$ & $16(21.6 \%)$ & - & $23(31.1 \%)$ & $19(25 / 7 \%)$ & 74 \\
\hline Right ventricle dilation & $13(68.4 \%)$ & $1(5.3 \%)$ & $1(5.3 \%)$ & 1 & $4(21.1 \%)$ & 19 \\
\hline
\end{tabular}

The medical areas that benefit most from this concept are those in which the time factor is important.

The present study examines aspects of standardized training clinical ultrasonography performed at the Faculty of Medicine, University of Lleida, in order to know the characteristics of the students, know their capacity to identify serious or fatal heart disease and the suitability of the view used in the videos (subcostal), all of them for the course and for clinical application.

Material and methods: Standardized training in clinical ultrasonography, with a duration of 25 hours, for physicians without experience in ultrasonography and who attend patients with acute, urgent and critical conditions. The teaching methodology consists in a brief theoretical presentations followed by practical sessions in small groups (4-5 students) about ultrasonography, different benefits, monitor expert. They used live models and simulators. One hour of theory and two of practice are dedicated to echocardiography.

The course is assessed with a standardized practical and theoretical examination. Before an after de course all students respond a survey related to their previous knowledge, use and availability of this technique. A part of the evaluation consists of four videos of echocardiography in a subcostal view, 3 of them with life-threatening disease and a normal one, for 10 seconds. They had no available prior information of the case and only the image must be interpreted by the student and suggest a diagnosis.

Data was analyzed using SPSS v.17.

Results: A total of 289 students attended to this course. 4 has been removed from or study because didn't answered the exam or the survey, leaving a sample of 285 students. In the survey $95.5 \%$ rated as high the need for ultrasound in emergency services. There is a significant relationship $(p<0.05)$ between the availability of radiologist in the hospital and the need to use ultrasound in the ED. $86.7 \%$ achieved optimal viewing at subcostal point. The $80.7 \%$ of students committed one or none error in the questions videos about heart disease. The following tables summarizes the number of students which correctly respond each video an in the response in that students who didn't answered correctly. Tables 1 and 2.

Discussion and conclusions: $95 \%$ of physicians who work in ED found useful the knowledge and use of ultrasonography. Those who work in hospitals considered more basic found the knowledge of this technique more useful. Most of the students achieved a correct visualization from the subcostal point, which correlates with other studies and publications in the bibliography. Would therefore be recommend as the initial view in a situation of AESP. The videos with a major percentage of errors are the severe hypocontractiblity and the healthy hearth, in contrast a more than $90 \%$ of students identified the pericardial effusion and the dilatation of right ventricle, which are potentially treatable diseases in CPR contexts. These results support the thesis that a short course can help to identify potentially treatable pathology in a PEA context.

\section{A22}

\section{The pericardium horror show}

Ramon Nogué Bou*, J Fabregat, R Vilella, A Encinas, T Villen, R Campos

Hospital Montserrat, University of Lleida, Alcalde Sol, № 6-3. Lleida, Spain E-mail: rnogueb@gmail.com

Critical Ultrasound Journal 2012, 4(Suppl 1):A22

We describe three cases where the ultrasonography "point of care" was decisive.

Case 1: 83 year old woman with a history of hypertension and stroke, who were admitted to our hospital for right hemiplegia with an evolution of more than 3 hours. She shows us a report that two days earlier was admitted in another center for an episode of atrial fibrillation at $150 \mathrm{bpm}$ of less than 48 hours of evolution, where he underwent electrical cardioversion reverting to sinus rhythm at $72 \mathrm{bpm}$ and anticoagulation with heparin of low molecular weight was started.

Physical examination: BP 114/76 mmHg, HR 72 bpm, Temp: $36.6^{\circ} \mathrm{C}$, Sat 02: $97 \%$.

Cardiac auscultation: arrhythmic tones, systolic murmur. Jugular venous distention. Right hemihipoestesia and hemiparesia, dysarthria. No other remarkable findings.

Evolution: Diagnosed with stroke, is admitted to our center. During the following day she presented several episodes of hypotension which responded to fluid therapy. An ultrasonography guided central line placement, for better control was decided. At this point significant jugular distension and slow and turbulent flow visible without Doppler was detected. Given these findings without clear signs of cardiac failure, an obstruction at lower level was suspected. We decided to perform an echocardiography. A pericardial effusion, which was not present in an echocardiography performed ten days ago, was detected.

Clinical trial: Pericardial effusion post-cardioversion.

Treatment: We performed ultrasound-guided pericardiocentesis, obtaining $160 \mathrm{ml}$ of sero-hematic liquid. After that the patient showed progressive improvement with recovery of blood pressure levels.

Case 2: 82 year old woman with a history of 3rd degree AV block with a pacemaker placed 20 days before the current admission.

She complains of dizziness similar to those presented before pacemaker implantation, accompanied by thoracic discomfort.

Physical examination: TA: 100/80 mmHg, HR 80 bpm, O2 Sat: 94\%.

Cardiac auscultation: rhythmic sounds, without murmurs. Lung auscultation: basal crackles. Jugular venous distention. No other remarkable findings.

Investigations: ECG: 3rd degree AV block, left bundle branch block with HR $78 \mathrm{bpm}$. Peacemaker spikes not correlated with $\mathrm{P}$ waves or QRS complexes. Chest radiography: cardiomegaly. Peacemaker catheter on right ventricle. Evolution: Given the findings on ECG, we decided to perform an echocardiogram to check the placement of the pacemaker, although it appears correct in the chest radiograph. We found the end of the catheter into the pericardium, accompanied with a minimal effusions an a perforation of the right ventricle wall.

Treatment: We call the cardiologist, who retired the catheter.

Case 3: 43 year old woman presented hemodynamic deterioration during the postoperative of hemicolectomy for colon cancer.

Physical examination: TA: $89 / 58 \mathrm{mmHg}$, HR 134 bpm.

Abdomen soft, depressible. No pathological products present into colostomy bag. Jugular venous distention. No other remarkable findings.

Evolution: Assuming diagnosis of hypovolemic shock fluid therapy was initiated, with worsening of the hemodynamic status. The surgeon did not found any abdominal or surgical complication.

Given the presence of jugular venous distention, echocardiography was decided, objectifying pericardial effusion. In ultrasound guided pericardiocentesis a transparent liquid was extracted. In biochemistry showed an ion concentration similar to physiologic saline.

Diagnostic judgment: Central line catheter complication.

Treatment: Given the findings fluid infusion was suspended, and central line retired $3 \mathrm{~cm}$, presenting hemodynamic improvement. It is therefore assumed that the central line was placed in the pericardium, being the cause of the effusion.

Conclusions: The three cases have exposed three facts in common: first, the presence of pericardial effusion initially unsuspected. Second, the difficulty to suspect this condition without ultrasonography. And third, its easy detection by bedside echocardiography, which changed the treatment, avoiding potential aggravation. 
This highlights the important role of ultrasonography and its progressive introduction in the emergency services, enabling rapid detection of diseases by the staff using protocols.

\section{A23}

Mediastinic perforation by hemodialysys catheter during the procedure. A case report.

Maria Farré Pinilla*, S Enriquez Bargalló, N Garcia Ruiz, P Espachs Biel,

J Vilà Justribó, A Montero Matamala

Department of Anesthesiology, Hospital Arnau de Vilanova, Lleida, Spain

E-mail: mfpinilla@gmail.com

Critical Ultrasound Journal 2012, 4(Suppl 1):A23

We present the case of a patient, 60 years old, which has been carrying multiple central venous catheters for hemodialysis. We recived consultation: the patient need a central vascular access. He has malfunctioning of femoral dialysis catheter, central catheter in left internal jugular vein removed a week ago, the right jugulosubclavian territory with thrombosis.

We try cannulation of left internal jugular vein, with ultrasound and radiologic guidance.

During the procedure, the patient experienced sudden and intense chest pain, which disappear spontaneously in a few seconds. At the end of the procedure one of the catheter's lights was malfunctioning. Before starting hemodialysis the chest pain is reproduced by serum injection. Rx appropriate check. Chest CT is performed and it shown the vascular perforation. The patient suffer mediastinic perforation due to catheter of $14^{\prime} 5 F$, into the left brachiocephalic vein. The vascular perforation is in the same area of permcath kink previous.

Discussion: Several mechanical complications associated with central venous catheters, even using ultrasonography and radiology during the procedure, are reported.

It is essential to have a high index of suspicion in patients with known vascular diseases, carriers of thick catheters for long periods, especially left approaches. This creates particular vulnerability to serious complications as vascular perforation.

References

1. Merrer J, Lefrant JY, Timsit JF: How to improve central venous catheter use in intensive care unit? Ann Fr Anesth Reanim 2006, 25(2):180-8.

2. Martínez A, López LA, Rodríguez JM, Cacho E, Pueyo FJ, Monedero P. Mediastinitis tardía con hidrotórax bilateral tras perforación vascular por catéter venoso central. Rev. Esp. Anestesiol. Reanim 2005, 52:634-636.

3. Banerjee A, Bhowmick K, Nayagam M, Farrington K: Late atrial perforation from tunnelled haemodialysis catheter. QJMed 2010, 103:527-529.

4. Kotsikoris I, Zygomalas A, Papas T, Maras D, Pavlidis P, Andrikopoulou M, Tsanis A, Alivizatos V, Bessias N: Insertion of central venous catheters for hemodialisis using angiographic techniques in patients with previous multiple catheterizations. Eur J Radiol 2012, 81(9):2270-2272.

\section{A24}

A complication of port-a-cath: disconnection and migration of central venous catheter to pulmonary artery. A case report.

Maria Farré Pinilla*, S Enriquez Bargalló, N Garcia Ruiz, P Espachs Biel,

J Vilà Justribó, A Montero Matamala

Department of Anesthesiology, Hospital Arnau de Vilanova, Lleida, Spain

E-mail: mfpinilla@gmail.com

Critical Ultrasound Journal 2012, 4(Suppl 1):A24

A 50 year old woman, with breast cancer undergoing chemotherapy. Login to removal because of the disconnection between the catheter and the subcutaneous port, diagnosed in routine check. In this case the X-ray showed the disconnection between the catheter and the subcutaneous port. And the consequent migration of the catheter, through cardiac cavities, into the pulmonary artery. Embolized catheter was removed by interventional radiology, under local anesthesia and intravenous sedation. The retrieval of the fragment was performed successfully using a snare catheter passed through the right femoral vein.

Discussion: The central venous cannulation and placement of permanent vascular access is a common technique in cancer patients. This is an invasive procedure, non-therapeutic or curative in itself, which can lead to serious complications, even death.

The iconography of this case demonstrates a mechanical complication, potentially severe and rare placement of a port-a-cath. Embolized catheters can be removed by interventional radiology without significant adverse affects. The patient recovered without complications.

References

1. Subramaniam A, Kim KH, Bryant SA, Kimball KJ, Huh WK, Straughn JM, Estes JM, Alvarez RD: Incidence of mechanical malfunction in low-profile subcutaneous implantable venous access devices in patients receiving chemotherapy for gynecologic malignancies. Gynecol Oncol 2011, 123(1):54-7, Epub 2011 Jul 13.

2. Heibl C, Trommet V, Burgstaller S, Mayrbaeurl B, Baldinger C, Koplmüller R, Kühr T, Wimmer L, Thaler J: Complications associated with the use of Port-a-Caths in patients with malignant or haematological disease: a single-centre prospective analysis. Eur J Cancer Care (Engl) 2010, 19(5):676-81, Epub 2009 Aug 25.

3. Surov A, Wienke A, Carter JM, Stoevesandt D, Behrmann C, Spielmann RP, Werdan $K$, Buerke M: Intravascular embolization of venous cathetercauses, clinical signs, and management: a systematic review. JPEN J Parenter Enteral Nutr 2009, 33(6):677-85, Epub 2009 Aug 12.

4. Debourdeau P, Zammit C, Pavic M, Bensaid B, Farge-Bancel D: Venous thromboembolism associated with long-term use of central venous catheters in cancer patients. Rev Med Interne 2007, 28(7):471-83, Epub 2007 Apr 19.

\section{A25}

Test characteristics of thoracic point of care ultrasonography for the diagnosis of acute congestive heart failure in the emergency department

Muhammad Tashkandi', Michael Woo, Christian Vaillancourt

Department of Emergency Medicine, University of Ottawa, Ottawa, Ontario, Canada

E-mail: dr.muhammad@gmail.com

Critical Ultrasound Journal 2012, 4(Suppl 1):A25

Introduction: The test characteristics of thoracic Point of Care Ultrasonography (PoCUS) for the diagnosis of acute congestive heart failure (CHF) are not well known, and no prior study evaluated the diagnostic impact of pleural effusions. We sought to determine the test characteristics of thoracic PoCUS when performed within 2 hours of initial emergency physician (EP) assessment by combining sonographic B-lines and pleural effusion to diagnose acute CHF.

Methods: This prospective cohort study used a convenience sample of adult patients presenting to the ED with suspected acute CHF. An EP not involved in the patients care performed an eight-zone thoracic PoCUS (Positive when B-lines seen in $>=2$ zones on each side). Two EPs blinded to thoracic PoCUS results performed a health record review that served as the criterion standard for CHF. We calculated the test characteristics of two (inferior lateral zones only) and eight-zone thoracic PoCUS with and without sonographic pleural effusion using stratified analysis with $95 \%$ confidence intervals (Cl).

Results: Of the 40 patients enrolled, 3 did not meet all inclusion criteria and were excluded. The mean age was 81 , males $51 \%, 84 \%$ diagnosed with CHF, 54\% arrived via EMS, $65 \%$ admitted, and 3\% intubated. Positive and negative likelihood ratios, Sensitivity, and Specificity for the 37 patients analyzed are: 1) Eight-zone PoCUS: infinity; 0.35 (95\% Cl 0.22-0.57); $64.5 \%$ (95\% Cl 45\%-80\%); $100 \%$ (95\% Cl 51\%-100\%); 2) Eight-zone PoCUS with pleural effusion: infinity; 0.26 (95\% Cl 0.14-0.47); $74 \%$ (95\% CI 55\%87\%); $100 \%$ (95\% Cl 51-100\%); 3) Twozone PoCUS: 4.43 (95\% Cl 0.7-27.7): 0.43 (95\% Cl 0.26-0.71): $63 \%$ (95\%Cl 44\%-79\%): $86 \%$ (95\% Cl 42\%-99\%); 4) Twozone PoCUS with pleural effusion: $5.4(95 \% \mathrm{Cl}$ 0.9-32.5); $0.11(95 \% \mathrm{Cl}$ 0.03-0.36); 90\% (95\% Cl 73\%-97\%); 83\% (95\% Cl 36\%-99\%).

Conclusion: The test characteristics of thoracic PoCUS are improved with the inclusion of sonographic pleural effusion. There is a role for thoracic PoCUS in the diagnosis of acute CHF.

\section{A26}

Low cost ocular ultrasound phantom for the training in the diagnosis of the emergency eye pathology

Jorge Luis Cuévas Gonzales

Ultrasound Working Group (UWG) Emergency Department, Sanitas La

Moraleja Hospital, Madrid, Spain

E-mail: cuevitas72@gmail.com

Critical Ultrasound Journal 2012, 4(Suppl 1):A26 
Background: For several years modern technology allows the manufacturing of anatomical models that accurately simulate the features anatomical human body, their pathologies and in some cases their physical properties in what regards to the ultrasound. Today exist in the market a variety of anatomical models called Phantoms, created with the purpose of increasing the skills of the emergency physician in the use of the ultrasound as diagnostic and therapeutic tool. But on the other hand, these phantoms is not within the reach of all stakeholders, due to its high cost.

Objective: This poster summarizes the development of a low cost phantom of the human eye for ultrasound, with the purpose of obtaining a useful and economical alternative for training, teaching and learning in ultrasonographic diagnosis of the more often ocular patholology seen in emergency services. The method to make this kind of models of gelatine has already been described before, but which is described in this poster provides as a novelty, the manufacture and use of metal molds, as well as other details that give the phantom a great detail as to the quality of the ultrasound image, finish end and therefore to its practical purpose.

Materials and ingredients: Unflavored gelatin, ethanol at 70\%, plastic microwave-safe bowl or Tupperware, bowl with measurement, aluminum paper, any lubricating oil to the skin, approximately $1 \mathrm{~mm}$ thick aluminum rod, $1.5 \mathrm{~cm}$ wide and $40 \mathrm{~cm}$ long (you can use a splint of Zimmer that withdraws the foam), spoon, electric hand mixer. Mixing bowl.

Elaboration: Mix in a large bowl, a concentrated solution of unflavored gelatin, water and ethanol. For $500 \mathrm{ml}$ of hot water, add 100 grams of gelatin and $30 \mathrm{ml}$ of ethanol as a preservative. To obtain greater or lesser amount of mixture you will only need to make the corresponding conversion ratios using a simple rule of three and if required you can add clothing artificial colorant to give desired color to the phantom. Mix it with the electric mixer for 2 minutes, allow to stand 30 minutes. Then remove the foam on the surface with a spoon. Fill the bowl or tupperware with the mix and let it cool for 2 hours in the fridge. Meanwhile a metal rod is used to shape the mold of the eyeball, making a circle with a small mound that will simulate the shape of the cornea, which will represent the sagittal plane to view it with the ultrasound. In the same way and with smaller pieces of metal, will be made molds of smaller structures as the lens, iris, the retina detached etc. Can be used as guide, ultrasound of normal eye or a drawing fron an anatomy book. In order to increase echogenicity of the shapes made, use the body oil to
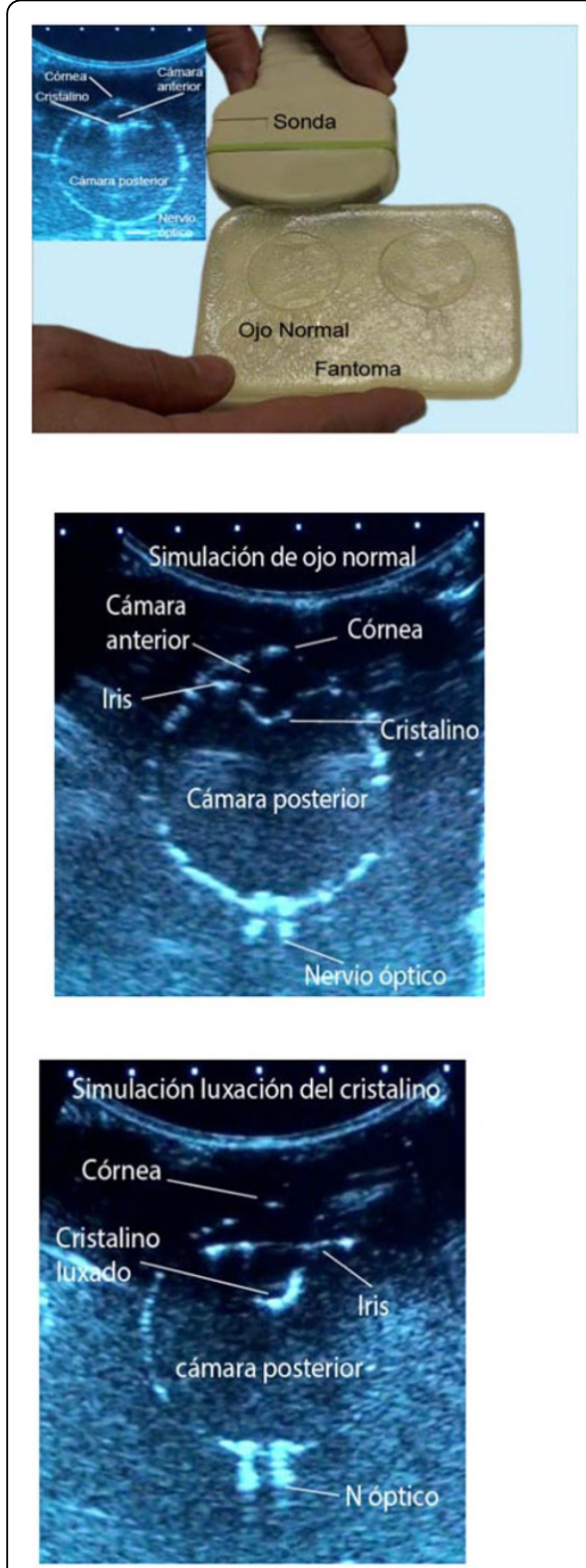
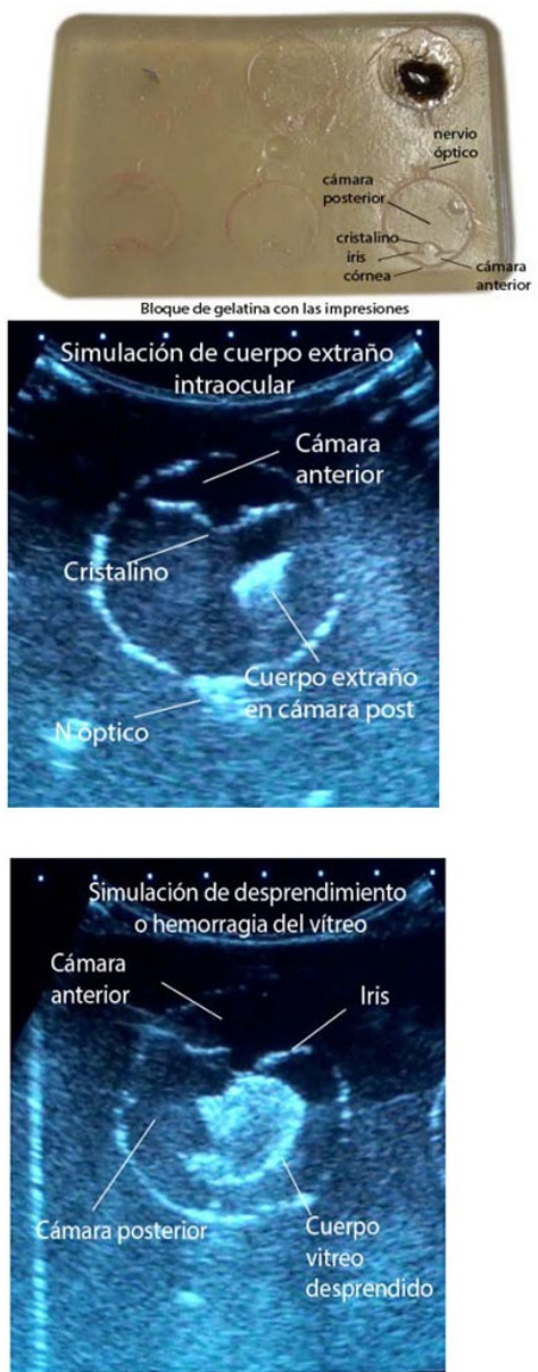
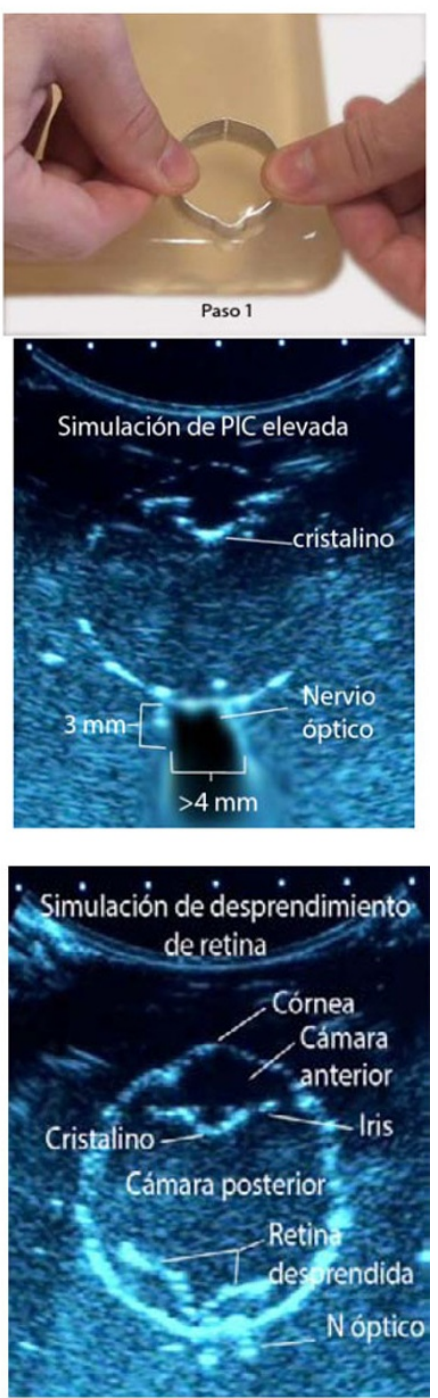
fill the prints in the already hard gelatin. 6 impressions of eyeballs for the different simulations will be made.

Procedures of making de ocular models: Normal eye: 1 print the eyeball mold on the already hard gelatin. 2 print the iris mold, what differentiates the anterior chamber from the rear chamber. 3 Print the posterior lens mold. 4 Print 2 parallel lines, separated by a maximum of $3 \mathrm{~mm}$. just behind what would be the back of the eye, parallel to the plane of the retina and immediately out of the eyeball that simulate the limits of the optic nerve. Body oil will be used in each print as a lubricant. Intraocular Foreign body: 1 the first 4 steps of the normal eye. 2 a piece of aluminum paper is embedded somewhere in the rear Chamber. Intracraneal presure elevation sign: 1 the first 3 steps of the normal eye. 2 The step 4 is done in the same way, but leaving one gap between the lines parallel. Approximately 4.5 to $5 \mathrm{~mm}$. The measure will be $3 \mathrm{~mm}$ behind the retina. Dislocation of the lens: 1 begins in the same way as for the normal eye. 2 Step 3 will be the impression of the Crystal in an axis not parallel to the iris. The rest of the steps are the same as the normal eye. Vitreous hemorrhage: 1 perform the same steps for the normal eye. 2 a part of representing the rear chamber is removed with a scalpel (1 to $1.5 \mathrm{~cm}$ in irregularly shaped) to the same depth of the impressions of the molds. Subsequently fills this gap with a mix of instant coffee and water. You can use elmer's glue instead of instant coffee which have high echogenicity. Retinal detachment: 1 perform the same steps as in the normal eye. 2 after the first stage, print the the retina detached with the corresponding mold or can be made directly with a scalpel making a irregular shape. To view with the ultrasound, left the unit on a horizontal surface and place the probe on the edge with the impression that you want to scan.

Results: Advantages: A block of transparent and durable gelatin in the medium-term (in cooling not freezing) is obtained, economic in which can be put into practice the handling of the probe, such as training in the recognition and ultrasonographic diagnosis of the more frequently eye pathology seen in emergency services. Each and every one of these molds are perfectly recyclable, so they can be melted again in the microwave for 3 to 4 minutes and then make new prints in the resulting gelatin block. Disadvantages: do not have long term durability and required store in cool place (fridge), as that the ambient temperature In the material rises handling can become friable. Eye ultrasound exploration is static and not dynamic, due to the eyeball does not move as in a real patient, the scan is performed only in the axial plane.

Conclusion: It is possible to achieve a training on ultrasound phantom of the eyeball with a better quality in terms of anatomy, physical and echographic properties, with acceptable durability, recyclable, economic, which allows the physicians to improve their skills in recognition of the most frequently emergency ocular pathology and therefore to improve the chances of patients to receive an accurate diagnosis and timely treatment.

\section{A27}

Acute appendicitis: echographic diagnosis at Emergency Department

Alberto Oviedo-García ${ }^{* *}$, M Algaba-Montes ${ }^{1}$, J Lopez-Libano

JM Alvarez-Franco ${ }^{3}$, N Diaz-Rodriguez ${ }^{4}$, A Rodriguez-Lorenzo ${ }^{5}$

${ }^{1}$ Emergency Department, Valme Hospital, Seville, Members of the Working Group of ultrasound SEMES_Andalucía and Semergen, Spain; ${ }^{2}$ Critical Care Department, Miramar Hospital, Mallorca, Member of the Working Group of ultrasound Semergen, Spain; ${ }^{3}$ Emergency Department, IB-Salut, Ibiza, Member of the Working Group of ultrasound, Semergen, Spain; ${ }^{4}$ Primary Care Barbadás Primary Care Center, Ourense, Member of the Working Group of ultrasound Semergen, Spain; ${ }^{5}$ Radiology Department, Perpetuo Socorro Hospital, Vigo, Member of the Working Group of ultrasound Semergen, Spain E-mail: albertoaog1972@hotmail.com

Critical Ultrasound Journal 2012, 4(Suppl 1):A27

Background: Acute appendicitis (AA) is the most frequent abdominal emergency surgery and the perforation, is mainly due to a delay in the diagnosis. The use of ultrasound (US) in Emergency Department (ED), could avoid delays in the diagnosis of this entity. When there is a perforation surgical morbidity multiplies by 15 and 50 the deaths.

Objective: We present a case of $A A$, diagnosed at ED, through the use of US scanning used by Emergency Physicians (EP), and promoting their use.
Patients and methods: A patient with abdominal pain, with a final diagnosis of an AA assessing ultrasound, performed by EP. We used a Sonosite M Turbo, equipped with probe Convex $\mathrm{C} 60$ between 2 and $5 \mathrm{MHz}$. Results: A male patient 18 years old, who attends the ED services, with abdominal pain, located all along his right side. No sign of nausea, vomiting or diarrhea, no fever or dysuria. He came in walking in the surgery, conscious and lucid, well hydrated and perfused, afebrile; abdominal tenderness presented an abdomen with voluntary defense in right hemiabdomen, no sign of peritoneal irritation. The rest of the exploration was normal. We have a slight leukocytosis of 10,900 without findings anywhere else in complementary tests. The patient continued with the same pain and the abdominal condition had not changed, so an abdominal US was performed, discovering an enlarged appendix, absence of peristalsis, not compressible, and the thickened wall.

Conclusion: Ultrasound carried out by EP, can be a very useful tool in cases for which clinic and analytics are not clear. The sensitivity of US for the diagnosis of AA is high, vary from 80 to $94 \%$, but is highly browser dependent and it is essential therefore, to have an appropriate training of the MU, to prevent diagnostic errors. To incorporate the US in ED decreases overall care time, since the EP is more efficient and dynamic, providing greater clinical safety and decreasing the complications.

Reference

1. Fox JC, Solley M, Anderson CL, Zlidenny A, Lahham S, Maasumi K: Prospective evaluation of emergency physician performed bedside ultrasound to detect acute appendicitis. Eur J Emerg Med 2008, 15(2):80-5.

\section{A28}

Complicated renal colic: usefulness of untrasonography in Emergency Department

Alberto Oviedo-García ${ }^{1 *}$, M Algaba-Montes' ${ }^{1}$, L Lopez-Libano²,

JM Alvarez-Franco ${ }^{3}$, N Diaz-Rodriguez ${ }^{4}$, A Rodriguez-Lorenzo ${ }^{5}$

${ }^{1}$ Emergency Department, Valme Hospital, Seville, Members of the Working Group of ultrasound SEMES_Andalucía and Semergen, Spain; ${ }^{2}$ Critical Care Department, Miramar Hospital, Mallorca, Member of the Working Group of ultrasound Semergen, Spain; ${ }^{3}$ Emergency Department, IB-Salut, Ibiza, Member of the Working Group of ultrasound Semergen, Spain; ${ }^{4}$ Primary Care, Barbadás Primary Care Center, Ourense, Member of the Working Group of ultrasound Semergen, Spain; ${ }^{5}$ Radiology Department, Perpetuo Socorro Hospital, Vigo, Member of the Working Group of ultrasound Semergen,

Spain

E-mail: albertoaog1972@hotmail.com

Critical Ultrasound Journal 2012, 4(Suppl 1):A28

Background: The renal colic (RC) is a common urological emergency, very painful, requiring prompt diagnosis and treatment. Over $12 \%$ of the population will experience a RC during their life, with the rate of recurrence by about $50 \%$. It is caused by an acute ureteral obstruction, which in most cases is usually due to a lithiasis, causing acute distension of the collecting system. Urinoma is an uncommon disease, caused by the extravasation of urine from any constituent of the urinary tract (kidney, ureter, urinary bladder or the urethra); it may be confined, encapsulated fluid collections or may manifest as free fluid.

Objetive: Abdominal ultrasound training in emergency department (ED). Patients and methods: We present the diagnosis of a RC with urinoma by ultrasound assessment in ED. We used a Sonosite M-Turbo ultrasound with Convex probe $\mathrm{C} 602-5 \mathrm{MHz}$ and abdominal ultrasound software.

Results: Abdominal ultrasound is a noninvasive, fast, portable, repeatable, and inexpensive method that gives us information on the degree of kidney affection pelvicalyceal ectasia can also diagnose complications such as urinoma. Urinoma is defined as an encapsulated collection of extravasated urine in the perirenal or paraureteral space, favored by the presence of an obstruction, provided that renal function is maintained. The most common causes of urinoma include obstructive uropathy, abdominal trauma with involvement of the urinary tract, inflammatory/malignant retroperitoneal, lithotripsy, nephrostomy or nonfunctioning kidney biopsy. One of the problems urinoma is the possibility of infection, thus complicating the development and may require surgery.

Conclusion: Incorporating ultrasound Health Centers could facilitate early diagnosis of complications of $\mathrm{CN}$, avoiding serious consequences, providing to the patient more clinic safety. 
Reference

1. Moak JH, Lyons MS, Lindsell CJ: Bedside renal ultrasound in the evaluation of suspected ureterolithiasis. Am J Emerg Med 2012, 30(1):218-21.

\section{A29}

Inferior vena cava diameters and collapsibility index changes reveal early volume depletion in a healthy donor model

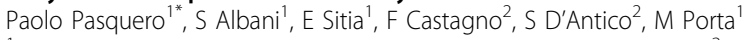

${ }^{1}$ Department of Medicine, S. Giovanni Battista Hospital, Turin, Italy; ${ }^{2}$ Blood

Bank, S. Giovanni Battista Hospital, Turin, Italy

E-mail: paolopasquero@libero.it

Critical Ultrasound Journal 2012, 4(Suppl 1):A29

Background: Measurement of the Inferior Vena Cava (IVC) diameters and collapsibility index $(\mathrm{Cl})$ for the detection of early volume depletion in healthy donors was recently investigated by Resnick et al. who showed no significant changes using different approaches after blood loss.

Objective: To investigate the usefulness of IVC diameters and $\mathrm{Cl}$ measurement to detect early volume depletion after blood loss of 400$450 \mathrm{ml}$ using different sonographic windows.

Patients and methods: 54 consecutive healthy donors were enrolled. 7 were excluded ( 1 for anaemia, 1 hypotension, 4 inadequate IVC visualization and 1 abnormal IVC dilatation).

Ultrasound measurements were obtained using M Mode, immediately before and as soon as possible after blood donation. Time from end of donation was recorded. Antero-posterior mid hepatic IVC diameter (long-axis and short-axis) were taken under the hepatic veins while distal IVC diameter was measured at the left renal vein junction. All data were fully recorded for a post processing study with an open source software (Image J).

Results: 47 donors (27 males, median age 38, median BMI 24.25) had satisfactory IVC visualization in $92.1 \%, 88.2 \%, 58.8 \%$ of cases for hepatic long-axis, hepatic short-axis and renal vein approach respectively.

No statistical difference between real time and post processing hepatic short-axis measurements was found. All mean IVC diameters decreased $(-19.3 \%,-19.8 \%,-25.9 \%$ in maximal diameters; $-30.3 \%,-32.4 \%,-34.7 \%$ in minimal diameters) and mean $\mathrm{Cl}$ increased $(+27.2 \%,+30.2 \%,+23.9 \%)$ for each window after blood letting $(p<0.00)$. Mid hepatic IVC long-axis revealed a correlation between the time after donation and $\mathrm{Cl}(20 \% \mathrm{Cl}$ decrease within 5 minutes until $0 \%$ after 20 minutes).

Conclusion: Both IVC diameters and $\mathrm{Cl}$ changes identified volume depletion in a healthy donor model. The mid hepatic long-axis window showed the best correlation between the IVC-CI and early volume variations following blood loss and post-donation volume repletion.

Reference

1. Resnick J, Cydulka R, Platz E, Jones R: J Emerg Med 2011, 41(3):270-5.
A30

Ecography guided puncture vs traditional puncture lancing: benefits for patients at risk in number of attempts to giving comfortable area Estefania Ruiz Chacon, Jordi Moreno Citoler*, Ramon Nogué Bou, Joan Pere Fabregat

Hospital Montserrat Lleida, Servicio de Urgencias y Cuidados Intermedios, Spain E-mail: jordirmc@gmail.com

Critical Ultrasound Journal 2012, 4(Suppl 1):A30

Aim: The purpose of this preliminary study is to verify the venipuncture technical using the ecography scanner and compared to the traditional puncture and how this first is beneficial for the patient decreasing the number of attempts and saving the affected puncture area.

Inclusion criteria: Including the patient risk and his pathology study: obesity, multipuncturation, respiratory pathology, cardiovascular pathology, patients with warfarina treatment; and convenient area of puncture, defining it as the area between radio-ulnar 1/3 distal and proximal radio-ulnar 1/3.

Method: A prospective study in two groups of patients with the abovementioned pathologies: 50 patients receiving traditional puncture and 50 patients receiving ecography guided puncture.

Results: Traditional puncture gets $56 \%$ success on the first try, while with ecography guided puncture the success increases to $72 \%$.

Traditional puncture on the second attempt we obtain a $34 \%$ and with ecography guided puncture we have a $26 \%$ of success.

We got, with the third attempt in traditional puncture, a $12 \%$ of success and through ecography guided puncture we have a $2 \%$ of success.

Fourth attempt to puncture through the traditional method is done in $2 \%$ patients while ecography guided puncture method the result is $0 \%$.

Conclusion: The percentage of success in the first ecography guided puncture is greater than the traditional method.

The percentage of success increases through the ecography puncture method meanwhile increases in the number of attempts.

The area where to place venous catheter is relevant to consider area of comfortable puncture for the patient described above.

With the same group of patients the choice of convenient area of puncture site was $92 \%$ entering in the above described area between distal radio-ulnar $1 / 3$ and proximal radio-ulnar $1 / 3$. The $8 \%$ remaining was in different areas of the upper limb.

Cite abstracts in this supplement using the relevant abstract number, e.g.: Ruiz Chacon et al:: Ecography guided puncture vs traditional puncture lancing: benefits for patients at risk in number of attempts to giving comfortable area. Critical Ultrasound Journal 2012, 4(Suppl 1):A30 